\title{
Morphology- and Crystalline Composition-Governed Activity of Titania-Based Photocatalysts: Overview and Perspective
}

\author{
Kunlei Wang ${ }^{1}$, Marcin Janczarek ${ }^{2}$, Zhishun Wei ${ }^{3}{ }^{\mathbb{D}}$, Tharishinny Raja-Mogan ${ }^{4}$, \\ Maya Endo-Kimura ${ }^{1}$, Tamer M. Khedr ${ }^{1,5}$, Bunsho Ohtani ${ }^{1,4}(\mathbb{D})$ and Ewa Kowalska $1,4, *(\mathbb{D})$ \\ 1 Institute for Catalysis (ICAT), Hokkaido University, N21 W10, Sapporo 001-0021, Japan; \\ kunlei@cat.hokudai.ac.jp (K.W.); m_endo@cat.hokudai.ac.jp (M.E.-K.); khedr.t@cat.hokudai.ac.jp (T.M.K.); \\ ohtani@cat.hokudai.ac.jp (B.O.) \\ 2 Institute of Chemical Technology and Engineering, Faculty of Chemical Technology, Poznan University of \\ Technology, 60-965 Poznan, Poland; marcin.janczarek@put.poznan.pl \\ 3 Hubei Provincial Key Laboratory of Green Materials for Light Industry, Hubei University of Technology, \\ Wuhan 430068, China; wei.zhishun@hbut.edu.cn \\ 4 Graduate School of Environmental Science, Hokkaido University, Sapporo 060-0810, Japan; \\ rajamogan.t@cat.hokudai.ac.jp \\ 5 Nanomaterials and Nanotechnology Department, Central Metallurgical Research and Development \\ Institute (CMRDI), P.O. Box 87 Helwan, Cairo 11421, Egypt \\ * Correspondence: kowalska@cat.hokudai.ac.jp
}

Received: 16 November 2019; Accepted: 7 December 2019; Published: 11 December 2019

\begin{abstract}
Titania photocatalysts have been intensively examined for both mechanism study and possible commercial applications for more than 30 years. Although various reports have already been published on titania, including comprehensive review papers, the morphology-governed activity, especially for novel nanostructures, has not been reviewed recently. Therefore, this paper presents novel, attractive, and prospective titania photocatalysts, including zero-, one-, two-, and three-dimensional titania structures. The 1D, 2D, and 3D titania structures have been mainly designed for possible applications, e.g., (i) continuous use without the necessity of particulate titania separation, (ii) efficient light harvesting (e.g., inverse opals), (iii) enhanced activity (fast charge carriers' separation, e.g., 1D nanoplates and 2D nanotubes). It should be pointed out that these structures might be also useful for mechanism investigation, e.g., (i) 3D titania aerogels with gold either incorporated inside the 3D network or supported in the porosity, and (ii) titania mesocrystals with gold deposited either on basal or lateral surfaces, for the clarification of plasmonic photocatalysis. Moreover, OD nanostructures of special composition and morphology, e.g., magnetic(core)-titania(shell), mixed-phase titania (anatase/rutile/brookite), and faceted titania NPs have been presented, due to their exceptional properties, including easy separation in the magnetic field, high activity, and mechanism clarification, respectively. Although anatase has been usually thought as the most active phase of titania, the co-existence of other crystalline phases accelerates the photocatalytic activity significantly, and thus mixed-phase titania (e.g., famous P25) exhibits high photocatalytic activity for both oxidation and reduction reactions. It is believed that this review might be useful for the architecture design of novel nanomaterials for broad and diverse applications, including environmental purification, energy conversion, synthesis and preparation of "intelligent" surfaces with self-cleaning, antifogging, and antiseptic properties.
\end{abstract}

Keywords: anatase; rutile; brookite; morphology; aerogels; photonic crystal; core-shell; mixed-phase titania; faceted titania; inverse opal 


\section{Introduction}

Titania (titanium(IV) oxide, $\mathrm{TiO}_{2}$ ) is one of the most famous and widely studied photocatalysts. Titania is a naturally occurring oxide of titanium, including anatase, rutile, brookite, $\mathrm{TiO}_{2}(\mathrm{~B}), \mathrm{TiO}_{2}(\mathrm{H})$, $\mathrm{TiO}_{2}(\mathrm{R})$, and akaogiite (new-found and exceedingly rare [1]) polymorphs. However, in nature, various mixtures of titania could be found, e.g., ilmenite (a black iron-titanium oxide with a chemical composition of $\mathrm{FeTiO}_{3}$, which is commonly used for titania synthesis via the sulfate method), rather than its pure crystals. Titania has been used extensively in our daily life, i.e., as a pigment, in the textile and paper industry, food, drugs, cosmetics, and as photocatalysts.

The application of titania for photocatalysis is probably the most important for future human development, since titania might be used to solve (at least in part) three out of 10 of humanity's top problems (problems proposed by Professor Smaley [2]), i.e., energy, environment, and water. Under irradiation with energy equal or larger than its bandgap, titania is excited with electron transfer from valence band (VB) to conduction band (CB), and thus formed charge carriers (electrons in $\mathrm{CB}$ and holes in VB) might either recombine or migrate to the surface, where they can initiate redox reactions. Accordingly, solar energy conversion into electricity or/and fuels (including "artificial photosynthesis"), water treatment, and environmental purification, which are mainly by formed reactive oxygen species (ROS), are initiated by photogenerated charge carriers (electrons and holes).

The unique photocatalytic properties of titania are not only impacted by its intrinsic physicochemical characteristics, but also by the morphological and structural properties of titania particles, and it is particularly important to consider them to design an efficient and applicable photocatalysts. Understanding the correlation between the mentioned properties and photocatalytic activity is still unsatisfactory, which contributes to the slow development of technologies based on photocatalysis. The vision of highly selective photocatalysts arising from the potential achievements in the considered issue would reach a crucial milestone in the titania application, including environmental purification, energy conversion, synthesis, and "intelligent" surfaces with self-cleaning, antifogging, and antiseptic properties.

A huge number of various reports on titania photocatalysts have been published annually (Figure 1a) for different applications, including several insightful review papers, e.g., Hashimoto et al. [3], Zaleska [4], Kowalski et al. [5], and Tsang et al. [6]. Despite these papers, there is still a lack of comprehensive review focusing on the influence of the morphology and the structure on the photocatalytic performance. Therefore, in this paper, special emphasis will be put on the novel trends in the architecture design of titania and titania-based photocatalysts, such as faceted titania, inverse opal, microspheres, aerogels, core-shells, and mixed-phase structures.

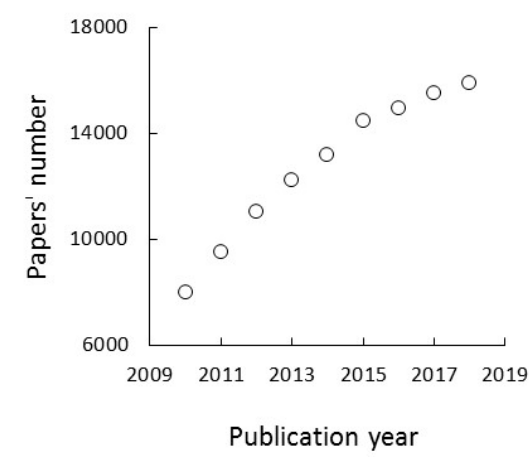

(a)

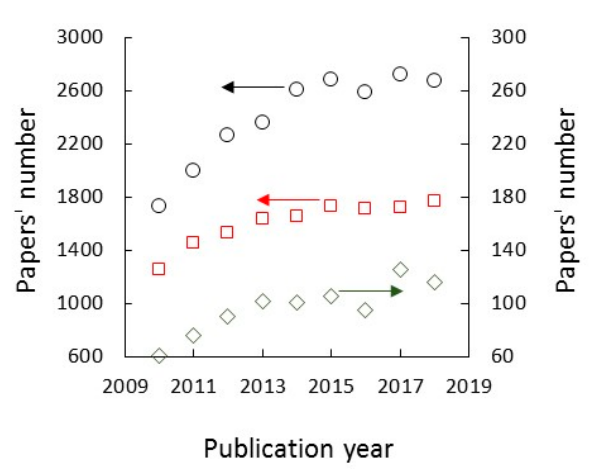

(b)

Figure 1. Number of papers published annually on: (a) titania (searched in Web of Science using "titania" or " $\mathrm{TiO}_{2}$ " or "titanium dioxide" or "titanium(IV) oxide") and (b) titania polymorphs: anatase $(\bigcirc)$, rutile $(\square)$, and brookite $(\diamond)$ (searched in Web of Science using "anatase", "rutile", and "brookite", respectively). 


\section{Titania Polymorphs and Mixed-Phase Samples}

\subsection{Photocatalytic Activity of Titania Polymorphs}

Two main polymorphs of titania, i.e., anatase and rutile (Table 1), have been extensively investigated both for photocatalysis and other applications (pigments, sunscreen creams), and recently, the high photocatalytic activities of brookite have been also reported [7,8]. Anatase, rutile, and $\mathrm{TiO}_{2}(\mathrm{H})$ belong to tetragonal system, brookite, and $\mathrm{TiO}_{2}(\mathrm{R})$ to orthorhombic, whereas $\mathrm{TiO}_{2}(\mathrm{~B})$ and akaogiite to monoclinic one (akaogiite will not be discussed in this paper, since its photoactivity has not been investigated yet.). Rutile is the most abundant and the most thermodynamically stable polymorph of $\mathrm{TiO}_{2}$; it is widely used in pigments and cosmetic products, mainly due to its high refractive index. In contrast, anatase and brookite are metastable, and thus thermal treatment results in their phase transition into rutile.

Anatase has been commonly reported as the most photocatalytically active form of titania; thus, it has been mainly investigated and used for many photocatalytic reactions, as shown in Figure 1b. Various reasons for its higher activity than other phases (including amorphous titania) have been proposed, such as a wider bandgap (and thus high oxidation and reduction ability), lower content of defects, higher content of hydroxyl groups on the surface, higher mobility of charges (i.e., mainly electrons), lower content of deep electron traps (ETs; and thus a lower rate of charge carriers' recombination). It should be also mentioned that usually anatase has a much larger specific surface area than rutile (higher temperatures of rutile preparation results in nanoparticles (NPs)' sintering and aggregation), and thus a larger content of adsorption sites for reacting molecules on its surface has been also proposed as another reason for its high photocatalytic efficiency.

The comparison of 35 titania photocatalysts showed that the photocatalytic efficiency did not depend only on the titania properties (specific surface area, polymorphic composition, defects' content, crystallite, and particle sizes), but also on the kind of photocatalytic reaction [9]. Accordingly, it has been proposed that (i) large particle sizes result in efficient oxygen evolution, (ii) large specific surface areas (small crystallite and particle sizes) result in methanol dehydrogenation, (iii) anatase presence results in the oxidative decomposition of acetic acid, (iv) rutile presence and defects' content result in the oxidative decomposition of acetaldehyde, and (v) rutile presence results in the synthesis of pipecolinic acid. Moreover, it should be pointed that mixed-phase rather than single-phase titania photocatalysts have been used in photocatalysis (as pure phase samples are rather rare), and thus the impact of the minor phase on the overall activity cannot be omitted. Interestingly, "phase-mixed" titania samples have been proposed as more active than single-phase samples [10-14], as discussed in Section 2.2.

Table 1. Properties of titania polymorphs.

\begin{tabular}{|c|c|c|c|}
\hline & Rutile & Anatase & Brookite \\
\hline atomic spacing $(\AA)^{a}$ & $\begin{array}{l}a=4.596 \\
c=2.958\end{array}$ & $\begin{array}{l}a=3.793 \\
c=9.510\end{array}$ & $\begin{array}{l}a=5.456 \\
b=9.182 \\
c=5.143\end{array}$ \\
\hline axial ratios & $\mathrm{a}: \mathrm{c}=1: 0.64388$ & $\mathrm{a}: \mathrm{c}=1: 2.50725$ & $a: b: c=0.5942: 1: 0.5601$ \\
\hline molecule/unit cell ${ }^{a}$ & 2 & 4 & 8 \\
\hline density $\left(\mathrm{g} \mathrm{cm}^{-3}\right)^{a}$ & 4.25 & 3.88 & 4.12 \\
\hline crystal system $^{a}$ & $\begin{array}{l}\text { tetragonal (ditetragonal } \\
\text { dipyramidal) }\end{array}$ & $\begin{array}{l}\text { tetragonal (ditetragonal } \\
\text { dipyramidal) }\end{array}$ & $\begin{array}{l}\text { orthorombic } \\
\text { (dipyramidal) }\end{array}$ \\
\hline bandgap $(\mathrm{eV})$ & $3.02^{d}$ & $3.23^{\mathrm{d}}$ & $3.14^{\mathrm{e}}$ \\
\hline $\begin{array}{ll}\text { absorption } & \text { calculated }^{\mathrm{b}} \\
\text { edge }(\mathrm{nm}) & \text { measured }^{\mathrm{c}}\end{array}$ & $\begin{array}{c}410 \\
413^{f}\end{array}$ & $\begin{array}{c}384 \\
388^{\mathrm{f}}\end{array}$ & $\begin{array}{c}395 \\
395^{\mathrm{e}}\end{array}$ \\
\hline
\end{tabular}

a-data from webmineral.com; b-calculated from bandgap energy; c-experimentally estimated from absorption spectra; $d-f$ - exemplary data (might slightly differ depending on properties): $d-[15] ; \mathrm{e}-[16] ; \mathrm{f}-[17]$. 


\subsection{Photocatalytic Activity of Mixed-Phase Titania}

Different kinds of mixed-phase titania have already been prepared by various methods (sol-gel, sonochemical, hydrothermal, etc.) from different titania precursors (titanium isopropoxide, titanium butoxide, $\mathrm{TiCl}_{4}$, etc.) for diverse applications (degradation of organic pollutants, water splitting, reduction of $\mathrm{CO}_{2}$, etc.), as shown in Table 2 .

Table 2. Mixed-phase $\mathrm{TiO}_{2}$ photocatalysts: synthesis method, specific surface area, and applications.

\begin{tabular}{|c|c|c|c|c|c|}
\hline Ti Precursor & Method & Crystalline Structure $^{\mathrm{a}}$ & BET $^{b}$ & Application & Ref. \\
\hline TIP & sol-gel & $\begin{array}{l}A(21 \%-86 \%) \\
R(14 \%-79 \%)\end{array}$ & $50-94$ & $\begin{array}{l}\text { degradation of } \mathrm{MB}, \\
\text { phenol, and } 4 \mathrm{ClP}\end{array}$ & [18] \\
\hline TIP & sol-gel & $\mathrm{A}(60 \%-83 \%) / \mathrm{B}(17 \%-40 \%)$ & 115 & conversion of $\mathrm{CO}_{2}$ & [19] \\
\hline $\mathrm{TIP}$ & sol-gel & $\begin{array}{c}\mathrm{A}(76.2 \%-84.6 \%) / \mathrm{B}(12.8 \%-3.8 \%) / \\
\mathrm{R}(0 \%-2.6 \%)\end{array}$ & $48-276$ & degradation of $\mathrm{MB}$ & {$[20]$} \\
\hline TIP & sol-gel & $\mathrm{A}(53 \%-96 \%) / \mathrm{R}(4 \%-47 \%)$ & $62-90$ & - & [21] \\
\hline TIP & sol-gel (+ US) & $\mathrm{A}(79.6 \%-91.6 \%) / \mathrm{B}(9.4 \%-20.4)$ & 75.5 & oxidation of acetone & [22] \\
\hline TIP & sonochemical & $\mathrm{A}(49.5 \%-60 \%) / \mathrm{B}(40 \%-50.5 \%)$ & $112-172$ & $n$-pentane oxidation & [23] \\
\hline TIP & EISA & $\mathrm{A}(29 \%-95 \%) / \mathrm{R}(5 \%-71 \%)$ & $145-161$ & generation of $\mathrm{H}_{2}$ & [24] \\
\hline $\mathrm{TIP} / \mathrm{HCl}$ & EISA & $\begin{array}{c}\mathrm{A}(36 \%-70 \%) \\
\mathrm{R}(19 \%-61 \%) / \mathrm{B}(3 \%-25 \%)\end{array}$ & $96.1-77.8$ & water splitting & [25] \\
\hline $\mathrm{TBu}$ & sol-gel & $\mathrm{A}(65.5 \%-80.1 \%) / \mathrm{R}(17.7 \%-34 \%)$ & 134-169 & $\mathrm{CH}_{3} \mathrm{OH}$ oxidation & [26] \\
\hline $\mathrm{TBu}$ & sol-gel & $\mathrm{A}(18.1 \%-73.3 \% / \mathrm{R}(16.8 \%-52.7 \%)$ & $35-165$ & phenol degradation & [27] \\
\hline $\mathrm{TBu}$ & $\begin{array}{l}\text { sol-gel and } \mathrm{H}_{2} \\
\text { plasma }\end{array}$ & $\mathrm{A} / \mathrm{B}$ & $271.8-427.5$ & $\begin{array}{c}\text { degradation of } \\
\text { phenol, RhB and RB5 }\end{array}$ & [28] \\
\hline $\mathrm{TBu}$ & hydrothermal & $\mathrm{A}(72 \%) / \mathrm{R}(28 \%)$ & 54.1 & lithium-ion batteries & [29] \\
\hline $\mathrm{TBu}$ & hydrothermal & $\mathrm{A} / \mathrm{B}$ & $129-174$ & HCHO degradation & {$[30]$} \\
\hline $\mathrm{TBu}$ & hydrothermal & $\mathrm{A}(64.9 \%) / \mathrm{R}(35.1 \%)$ & 260 & $\begin{array}{l}\text { MB degradation, } \mathrm{H}_{2} \\
\text { evolution }\end{array}$ & [31] \\
\hline $\mathrm{TBu}$ & $\begin{array}{l}\text { hydrothermal } \\
\text { self-assembly }\end{array}$ & $\begin{array}{c}\mathrm{A}(32-61.4 \\
\mathrm{R}(0 \%-20 \%) / \mathrm{B}^{\prime}(0 \%-48 \%)\end{array}$ & $104.3-129.9$ & reduction of nitrate & [32] \\
\hline $\mathrm{TBu}$ & $\begin{array}{l}\text { coordination- } \\
\text { self-assembly }\end{array}$ & $\begin{array}{l}A(40 \%-77 \%) \\
R(23 \%-60 \%)\end{array}$ & $63.6-78.4$ & water splitting & [33] \\
\hline $\mathrm{TBu}$ & electrospinning & $\begin{array}{l}\mathrm{A}(94.6 \%) \\
\mathrm{R}(5.4 \%)\end{array}$ & 27.2 & $\begin{array}{l}\mathrm{H}_{2} \text { generation and } \\
\mathrm{RhB} \text { degradation }\end{array}$ & {$[34]$} \\
\hline $\mathrm{TBu} / \mathrm{TiCl}_{4}$ & EISA & $\mathrm{A}(73 \%-98 \%) / \mathrm{R}(2 \%-27 \%)$ & 92-135 & phenol degradation & [35] \\
\hline $\mathrm{TBu} / \mathrm{TiCl}_{4}$ & EISA & $\mathrm{A}(64 \%-91 \%) / \mathrm{R}(9 \%-30 \%)$ & 90-118 & water splitting & [25] \\
\hline $\mathrm{TBu} / \mathrm{TiCl}_{4}$ & EISA & $\mathrm{A}(74 \%-92 \%) / \mathrm{R}(8 \%-26 \%)$ & 73 & $\mathrm{H}_{2}$ generation & [36] \\
\hline $\mathrm{K}_{2} \mathrm{Ti}_{2} \mathrm{O}_{5}$ & $\begin{array}{l}\text { soft-chemistry } \\
\text { template-free }\end{array}$ & $\mathrm{A} / \mathrm{B}^{\prime}$ & 129 & $\begin{array}{c}\text { degradation of } \\
\mathrm{CHCl}_{3} \text { and } \mathrm{H}_{2} \\
\text { generation }\end{array}$ & [37] \\
\hline $\mathrm{Ti}_{2}\left(\mathrm{SO}_{4}\right)_{3}$ & hydrothermal & $\mathrm{A}(64 \%-87 \%) / \mathrm{B}(13 \%-36 \%)$ & $30-72$ & IBU degradation & [38] \\
\hline $\mathrm{Ti}_{2}\left(\mathrm{SO}_{4}\right)_{3}$ & hydrothermal & $\mathrm{C} / \mathrm{N}-\mathrm{A} / \mathrm{B}$ & $20.5-66$ & MC-LR degradation & {$[39]$} \\
\hline $\mathrm{Ti}_{2}\left(\mathrm{SO}_{4}\right)_{3}$ & hydrothermal & $\begin{array}{l}\mathrm{A}(61.8 \%) \\
\mathrm{B}(38.2 \%)\end{array}$ & 62.3 & $\begin{array}{l}\text { IBU, 4AAP, CYN, } \\
\text { and MC-LR } \\
\text { degradation }\end{array}$ & [40-43] \\
\hline
\end{tabular}

Crystalline structure ${ }^{\mathrm{a}}$ —A: anatase, $\mathrm{B}$ : brookite, $\mathrm{R}$ : rutile, $\mathrm{B}^{\prime}: \mathrm{TiO}_{2}(\mathrm{~B}) ; \mathrm{BET}^{\mathrm{b}}$ - specific surface area $\left(\mathrm{m}^{2} \mathrm{~g}^{-1}\right)$; TIP—titanium isopropoxide; $\mathrm{TBu}$-titanium butoxide; US-ultrasounds; EISA-Evaporation-induced self-assembly (EISA); RhB - Rhodamine B; MB - methylene blue; 4ClP-4-chloro phenol; RB5—reactive black 5; MC-LR — microcystin-LR; CYN—cylindrospermopsin; IBU—ibuprofen; $4 \mathrm{AAP} — 4$-amino antipyrine.

Titania P25, known also as Degussa P25, Evonik P25, and Aeroxide P25, is probably the most famous mixed-phase titania, due to its extremely high photocatalytic activity in various photocatalytic reactions. For example, P25 was used for the decomposition of organic [44-50] and inorganic [51] compounds present in water and wastewater, the degradation of gas-phase pollutants [52-56], the purification of indoor environments (e.g., allergens' removal [57]), inactivation of microorganisms [58-63], self-cleaning 
surfaces [64-66] and solar energy conversion [67]. The number of cited papers using "P25"and "photocatalysis" as keywords has exceeded 10,000 per year, as shown in Figure 2.

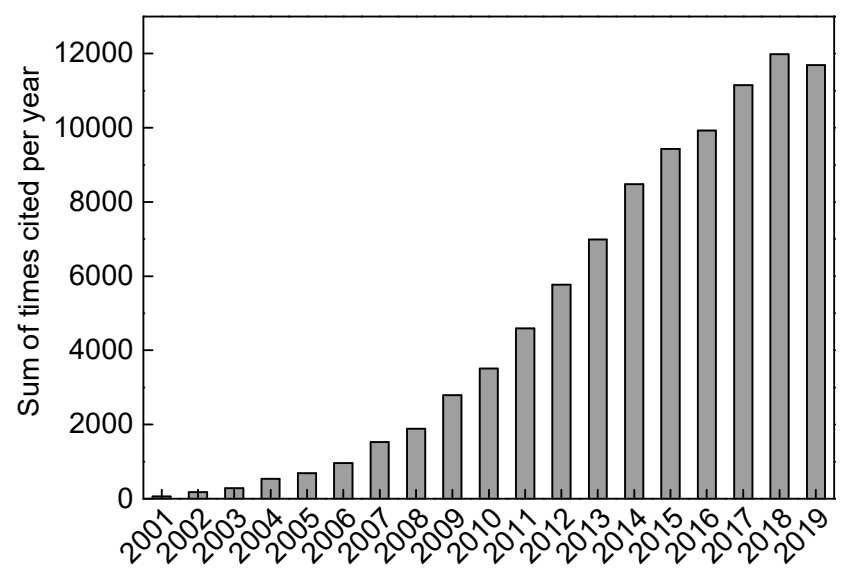

Figure 2. Number of cited papers published annually on: P25 photocatalysis (searched in Web of Science using: "P25" and "photocatalysis"; November 2019).

P25 is a white powder with fine NPs (ca. $30 \mathrm{~nm}$ ) and hydrophilic nature, and thus its surface is coated with hydroxyl groups. Fine NPs form aggregates, in which primary NPs are loosely bound together. The density and specific surface area of P25 reached ca. $3.9 \mathrm{~g} \mathrm{~cm}^{-3}$ and ca. $50 \mathrm{~m}^{2} \mathrm{~g}^{-1}$, respectively $[68,69]$. The different composition of P25 might be found in the literature, i.e., $70 \%-85 \%$ anatase and $15 \%-30 \%$ rutile, and the content of the amorphous phase is usually not even considered [70-72]. It was reported that small crystals of anatase (ca. $25 \mathrm{~nm}$ ) surrounded the large crystals of rutile [73-75]. Although P25 is commonly used as "standard" titania photocatalyst for activity comparison between different titania samples $[69,74,76-80]$, the phase composition might vary between each P25 sample. Even P25 powders sampled from the same container possessed different content of anatase, rutile, and amorphous phase, i.e., $73 \%-85 \%, 13 \%-17 \%$ and $0 \%-13 \%$, respectively $[68,69]$, which is not surprising, since the composition depends on the flame conditions (and even the location of formed particles in the flame; P25 is produced by gas-phase flame synthesis). Therefore, for reliable comparison among samples, the homogenization of $\mathrm{P} 25$ powder has been proposed, resulting in the preparation of almost uniform sample, containing $78 \pm 0.3 \%$ anatase, $14 \pm 0.1 \%$ rutile, and $8 \pm 0.8 \%$ amorphous phase [68].

Many explanations and possible reasons for the high photocatalytic activity of P25 and other mixed-phase titania have been proposed. The most popular one deals with the charge carriers' transfer between different phases, resulting in the inhibition of charge carriers' recombination, which is commonly named the "synergistic effect" $[74,81,82]$. Although usually electrons' transfer from anatase to rutile has been proposed, due to the more negative CB of anatase than that of rutile [83-90], some reports have claimed an opposite direction of charges' migration, e.g., (i) holes from an anatase core to a rutile overlayer and opposite electron transfer [82], and (ii) electrons from rutile to lattice trapping sites in anatase [75,81,91,92]. Mi and Weng have proposed five possible band alignments in mixed-phase (anatase/rutile) titania, as shown in Figure 3 [93]. Interestingly, type V (CBs being aligned) has been suggested as the most probable structure, which is based on transient infrared absorption-excitation energy scanning spectroscopy data. Therefore, the direction of electron migration must be controlled by dynamic factors, such as particle size, the presence of electron/hole scavengers on either the surface of anatase or rutile, or both.

Other proposed reasons for the high photocatalytic activity of P25 include the presence of amorphous phase and/or impurities (e.g., iron cations) [94], its low content of trapping sites (slow charge carriers' recombination) [71], and its "excellent" surface properties (small NPs, large specific surface area, high crystallinity). However, it should be pointed out that P25 does not have the best surface properties among various titania photocatalysts, but it does have one of the best photocatalytic 
activities. Accordingly, titania photocatalysts with much better properties (larger specific surface area, smaller crystallites) than P25 showed lower photocatalytic activities. In 1991, Bickley et al. proposed that the high activity of P25 (and other mixed-phase titania photocatalysts) was caused by the enhancement in "the magnitude of the space-charge potential", as a result of the interface between different phases and localized electronic states in amorphous titania [82].

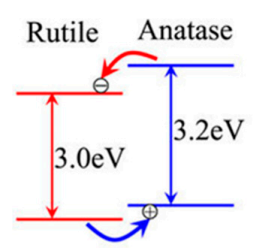

Type I : Staggered

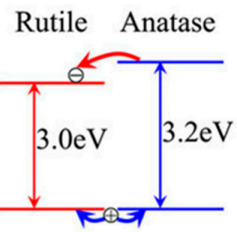

Type IV : VB Aligned

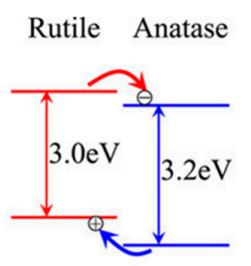

Type II : Staggered

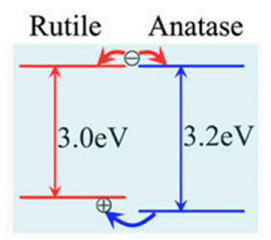

Type V : CB Aligned

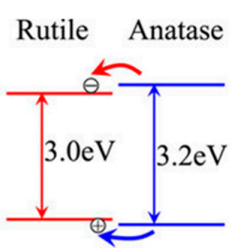

Type III : Included

Figure 3. Schematic diagram of possible band alignments between anatase and rutile. Reprinted with permission from [93]. Copyright 2015 Creative Commons Attribution.

Although it is unclear who first used the term "synergy" (or "synergistic effect") between anatase and rutile to explain the high activity of P25, many reports have used it interchangeably for an interparticle electron transfer (IPCT) between polymorphs in P25 and other mixed-phase titania photocatalysts [86,95-98]. However, commonly, no experimental evidence has been shown, and "synergy" has been only speculated based on the results showing a higher activity of mixed-phase titania than that of the single phase one. Moreover, in many cases, the activity of P25 (or other mixed-phase samples) was only slightly higher than that of the most active phase (usually anatase, depending on the reaction system), but not higher than the simple sum of its parts (activity of anatase plus activity of rutile- "synergy"). Therefore, even the term synergy has been used incorrectly in some reports.

Fortunately, some reports have tried to confirm a "synergistic effect" and/or IPCT for mixed-phase titania, mainly by the simple physical methods, such as mixing and thermal treatment. The phase mixing might be performed either in an aqueous suspension of different titania polymorphs or by grinding (It should be pointed that grinding might result in a slight change of surface properties, e.g., a decrease in particle size by abrasion). For example, Ohno et al. proved synergy between anatase and rutile for the photocatalytic oxidation of naphthalene for samples prepared by two methods, i.e., grinding (different ratios of anatase to rutile) and thermal treatment (influencing anatase-to-rutile phase transition) [11]. The synergetic effect was found in both kinds of samples (Figure 4), and IPCT was proposed as its main reason. Interestingly, the highest activity was obtained for mixed-phase titania, which was prepared by grinding with similar composition to that of P25 (Figure 4a). Therefore, it was suggested that similar "synergy" could be responsible for high activity by P25, i.e., electron transfer between anatase and rutile, resulting in a prolonged lifetime of charge carriers.

It is obvious that metastable anatase and brookite convert irreversibly into rutile upon heating. Therefore, during thermal treatment, the mixture of anatase and rutile can be easily obtained, e.g., anatase particles could be loaded with thermally formed rutile. For example, Zhang et al. proposed the synergy between anatase and rutile in the anatase-rutile mixed-phase sample, prepared by the calcination of anatase obtained by the precipitation method [99]. However, in that study, $\mathrm{La}_{2} \mathrm{O}_{3}$ was loaded on the surface of titania also; thus, a possible synergy between anatase and rutile could not be 
confirmed directly. Moreover, it should be pointed that thermal treatment might change not only the composition of samples (anatase/rutile ratio), but also all other properties, e.g., crystallite/particle size, specific surface area, morphology, defects' content. In some studies, "synergy" in P25 was suggested in comparison to anatase and rutile samples with quite different properties than those in P25, and usually these samples did not originate from P25 samples. Additionally, some activity tests have been carried out in the presence of loaded co-catalysts, and thus the properties of co-catalysts, which could be decisive for the overall activity, should be also considered.

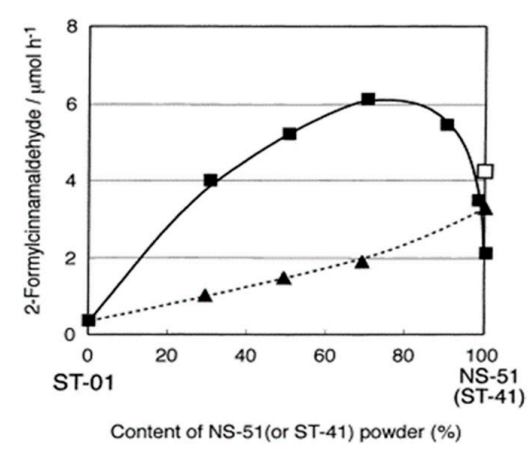

(a)

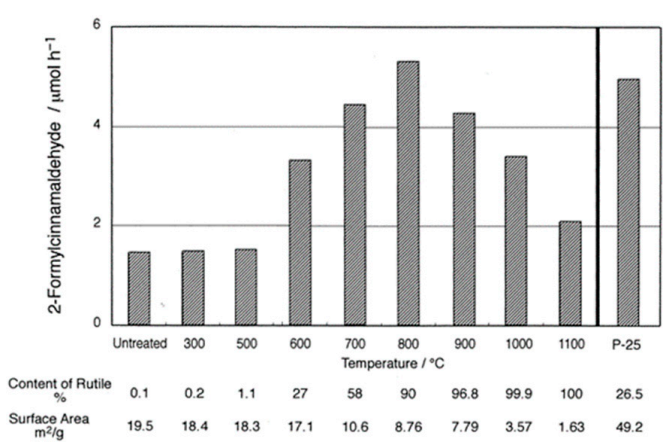

(b)

Figure 4. Synergism between anatase and rutile for: (a) grinded titania samples (synergism observed only for fine anatase ST-01 mixed with rutile NS-51 (घ), but not for two anatase samples: ST-01 and ST-41 ( $\mathbf{\Delta})$ ) and (b) anatase sample thermally treated (synergism observed for mixed-phase titania obtained at $700-900{ }^{\circ} \mathrm{C}$ containing $27 \%-96.8 \%$ rutile; Copyright 2013 Elsevier.

Although IPCT between anatase and rutile in P25 was suggested by electron paramagnetic resonance (EPR) spectroscopy $[75,81]$, the reference samples of anatase and rutile did not originate from P25, and thus it was impossible to decide unequivocally that IPCT was responsible for the high activity of P25. Accordingly, another approach was proposed by Ohtani, i.e., an isolation of rutile and anatase from P25 $[68,69,100]$. The successful isolation of crystalline phases by chemical methods, which was proposed first by Ohno et al. [101] and Ohtani et al. [100] for rutile and anatase isolation, respectively, was confirmed by various methods, e.g., XRD and diffuse reflectance spectroscopy (DRS), as shown in Figure 5 [68]. The photocatalytic activity data revealed another possible reason for the high activity by P25, i.e., the high intrinsic activity of anatase and rutile for different reactions. For example, anatase exhibited much higher activity than rutile and P25 for the oxidative decomposition of acetic acid and acetaldehyde, whereas rutile was the most active for oxygen liberation [69] and the dehydrogenation of methanol [68].

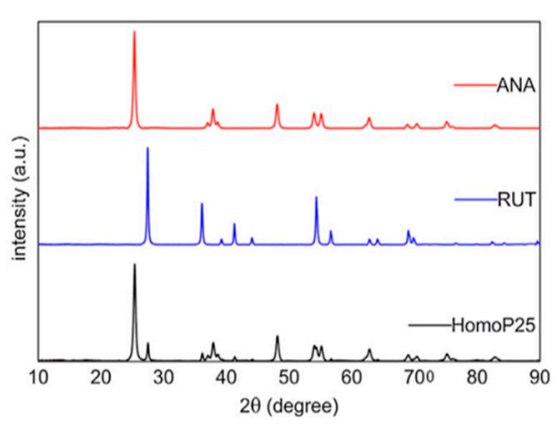

(a)

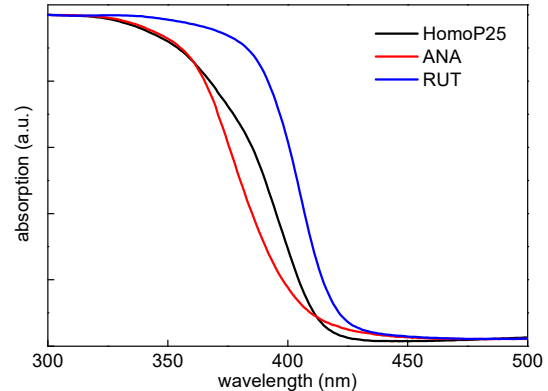

(b)

Figure 5. The properties of isolated samples and P25: (a) XRD patterns and (b) DRS spectra for anatase (ANA, red), rutile (RUT, blue) and P25 (HomoP25, black; P25 sample was first homogenized). Copyright 2018 Elsevier. 


\section{Nanostructured Titania: Zero-, One-, Two-, and Three-Dimensional Structures}

Titania and other nanomaterials could be classified according to their dimension confinement in nanoscale (usually defined as less than $100 \mathrm{~nm}$ ) measurements, and thus 0-dimensional (0D) might be referred to NPs, and nanospheres, whereas 1D and 2D have one and two dimensions larger than the nanoscale size, e.g., nanotubes and nanoplates, respectively. The structures with repeated bulk arrays could be designed as 3D titania, where none of their dimensions are confined to the nanoscale, except for their inner structure, e.g., composed of fine NPs, nanovoids, etc. Based on this concept, various types of titania nanostructures have been designed and reported. The most interesting, novel, and perspective examples are shortly presented in this chapter.

\subsection{Zero-Dimensional Titania}

Titania NPs (already presented in Section 2), nanospheres, nanorods, and nanorice NPs have been commonly used for photocatalytic reactions. Here, two kinds of nanostructures are shortly described, i.e., core-shells and faceted NPs.

\subsubsection{Core-Shell Titania Composites}

Core-shell titania nanostructures belong to titania composites, i.e., titania and other materials as mixed-phase composites. There are two main reasons for the preparation and usage of core-shells in photocatalysis, i.e., (i) reusability and (ii) enhanced activity. Although nanoparticulate titania is highly recommended for application, due to high activity (large specific surface area), the separation of the suspended photocatalyst might be costly (ultrafiltration). Therefore, photocatalyst supports, e.g., steel plates, molecular sieves, glass plates, Raschig rings, zeolites, activated carbon, and silica [102-105] have been applied. Glass microspheres recovered from fly ash were also used as titania support, and interestingly, higher activity was found for phenol degradation on microsphere/titania, despite it having a much lower surface area than that on particulate titania samples [106,107]. It was proposed that the composition of microspheres (the presence of $\mathrm{Fe}_{2} \mathrm{O}_{3}$ ) could influence the overall activity, i.e., the possible transfer of charges (both electrons and holes) from titania to $\mathrm{Fe}_{2} \mathrm{O}_{3}$ hindering charge carriers' recombination. However, it should be pointed out that there is a risk that titania support might be mechanically destroyed during photocatalytic tests (pumps, stirrers, etc.), as has been observed for these microspheres [106,108]. Therefore, a mechanically stable core has been proposed, such as magnetic $\mathrm{Fe}_{3} \mathrm{O}_{4}$, which additionally allows the fast and easy separation of photocatalysts after reactions in the magnetic field [109-111]. However, the photoreaction between a core and a shell might result in the instability of the photocatalyst (e.g., dissolution of iron), and thus an insulator interlayer has been applied by Zielinska-Jurek et al. between a magnetic core and titania shell, as shown in Figure 6 [110].

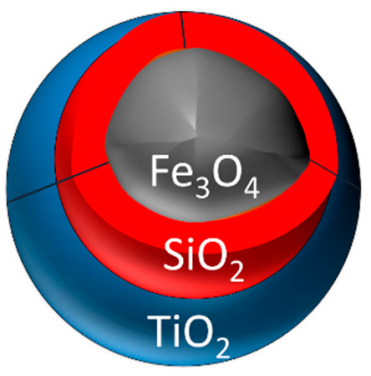

(a)

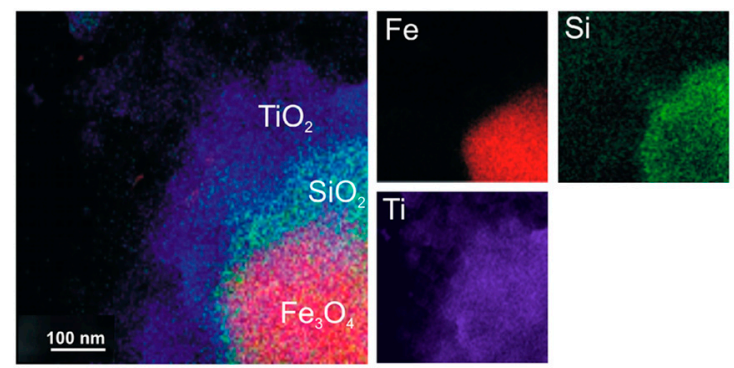

(b)

Figure 6. Core-interlayer-shell NPs composed of $\mathrm{Fe}_{3} \mathrm{O}_{4}$ (core), $\mathrm{SiO}_{2}$ (interlayer), and $\mathrm{TiO}_{2}$ (shell): (a) Nanostructure scheme; and (b) Mapping of $\mathrm{Fe}_{3} \mathrm{O}_{4}, \mathrm{SiO}_{2}$, and $\mathrm{TiO}_{2}$ in $\mathrm{Fe}_{3} \mathrm{O}_{4} / \mathrm{SiO}_{2} / \mathrm{TiO}_{2}$ ) photocatalyst prepared by the microemulsion method (Fe-red, $\mathrm{Si}$-green, and Ti-blue); adapted from [110]. Copyright 2017 Creative Commons Attribution. 


\subsubsection{Faceted Titania}

The concept of titania synthesis as crystals with specific facets has been a hot research topic, especially since 2008 when Yang et al. prepared anatase crystals with a large percentage of reactive \{001\} facets [112]. Earlier in 1998, Vittadini et al. theoretically predicted the exceptional dissociative adsorption of water on an anatase $\{001\}$ surface [113]. It is known that the reactivity of photocatalysts is strictly connected with a surface atomic arrangement and coordination, which determines the adsorption of reactant molecules, surface transfer between photoexcited electrons and reactant molecules, and finally the desorption of product molecules. The arrangement of crystal facets with different orientations changes the surface atomic arrangement and coordination, influencing the photocatalytic activity [114]. Pertaining to this, crystal facets engineering might be the solution for how to improve the usually poor selectivity of heterogeneous photocatalytic transformations by the minimization of dispersity of surface atomic structures [115].

Taking into consideration the surface energies of crystal facets, it is possible to estimate the equilibrium morphology of each titania polymorph using the Wulff construction theory [114], as shown for anatase, rutile, and brookite in Figure 7a-c. Accordingly, the equilibrium anatase shape is a slightly truncated bypiramid, which is enclosed with eight isosceles trapezoidal surfaces of $\{101\}$ and two $\{001\}$ facets located on the top/bottom of the crystal. The percentage of $\{001\}$ facets in this equilibrium crystal is $6 \%$. The surface energy of $\{001\}\left(0.90 \mathrm{~J} \mathrm{~m}^{-2}\right)$ is higher than for $\{101\}\left(0.44 \mathrm{~J} \mathrm{~m}^{-2}\right)[116,117]$. Among titania crystals, anatase faceted particles have been most intensively studied. It is possible to find research works where anatase crystals with low-index facets, such as $\{101\},\{001\},\{010\}$, and $\{110\}$, and high-index facets such as $\{103\},\{105\},\{107\},\{201\},\{401\},\{301\}$, and $\{106\}$ have been prepared. In the case of rutile crystals, the facets of $\{110\},\{011\},\{001\}$, and $\{111\}$ have been identified, whereas for brookite, the $\{100\},\{001\},\{101\},\{111\},\{210\}$, and $\{201\}$ facets have been achieved [117]. The main crystal shapes of anatase, rutile, and brookite are presented in Figure $7 \mathrm{~d}$.

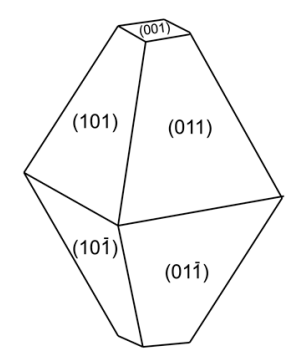

(a)

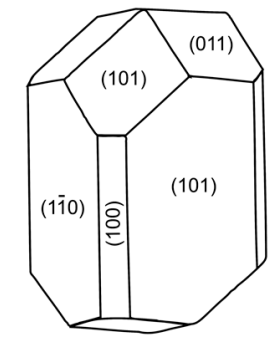

(b)

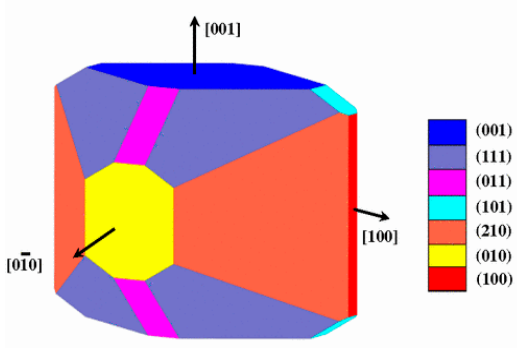

(c)

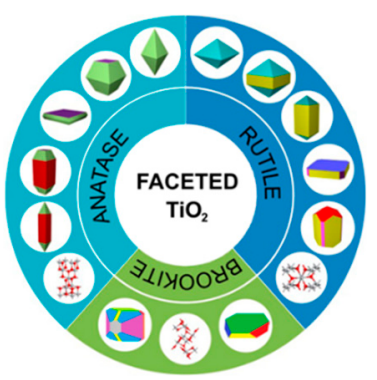

(d)

Figure 7. Equilibrium crystal shape of: (a) anatase (adapted with permission from [117]. Copyright 2011 American Physical Society); (b) rutile (adapted with permission from [118]. Copyright 1994 American Physical Society); (c) brookite (adapted with permission from [119]. Copyright 2007 American Physical Society); (d) Main crystal shapes of titania (adapted with permission from [117]. Copyright 2014 American Chemical Society).

Faceted $\mathrm{TiO}_{2}$ crystals can be prepared by different methods, such as the wet-chemistry route (hydrothermal, solvothermal) and gas oxidation route. The wet-chemistry approach commonly involves the application of fluorine-containing species (e.g., hydrogen fluoride, ammonium fluoride, titanium(IV) fluoride, and tetrafluoroborate ion) as morphology-controlling agents to achieve the resultant faceted particles [112,120]. Other compounds, including polyvinyl alcohol [121] and carbonate ions, are generated during the decomposition of urea [122], and sodium chloride and/or sodium perchlorate [123] have also been used to control the shape. Dinh et al. used oleic acid (OA) and oleyl amine $(\mathrm{OM})$ as capping agents with titanium n-butoxide $(\mathrm{TBu})$ as the titania precursor. Various shapes of titania-faceted particles (bar, dog-bone, rhombic, elongated rombic, truncated rombic) were obtained by controlling the ratio of TBu:OA:OM and the reaction temperature (Figure 8) [124]. 
However, the disadvantage of this approach is the strong adsorption of shape-control reagents (e.g., fluoride ions) on the crystal surface or their doping into the lattice, which may result in a decrease in photocatalytic activity [121]. Moreover, at high temperatures, fluorine compounds generate toxic and corrosive products.

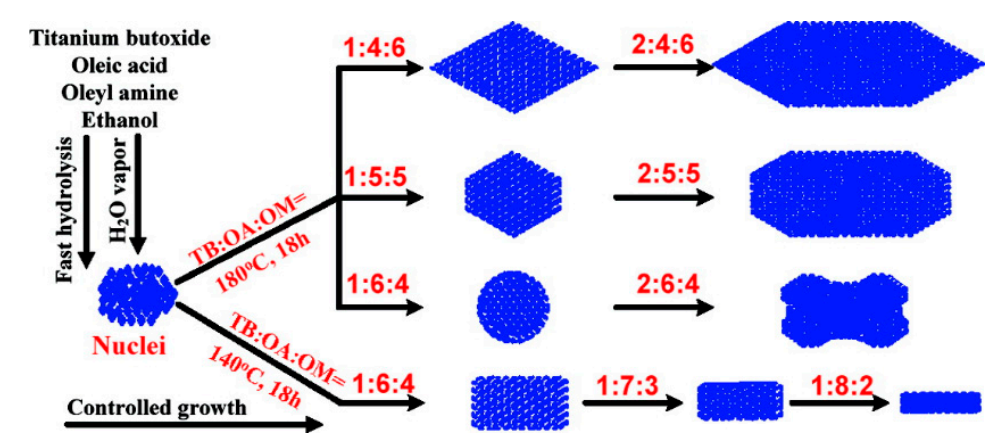

Figure 8. Shape-controlled preparation of faceted titania particles; adapted with permission from [124]. Copyright 2009 American Chemical Society.

The solution for these problems might be the development of methods based on gas-phase reactions $[78,125]$. The adjustment of one of the main parameters of gas-phase synthesis of decahedral anatase particles (DAP), e.g., concentration of titania precursor- $-\mathrm{TiCl}_{4}$ vapors, resulted in the morphological changes of the faceted particles (Figure 9).

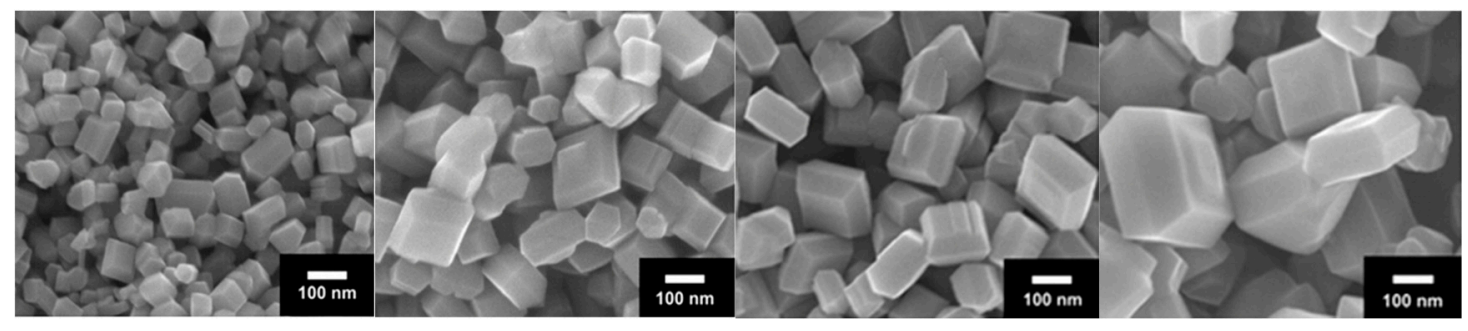

(a)

(b)

(c)

(d)

Figure 9. SEM images of decahedral anatase particles (DAP) samples prepared at different $\mathrm{TiCl}_{4}$ vapor concentrations: (a) $0.34 \mathrm{vol} \%$; (b) $0.86 \mathrm{vol} \%$; (c) $1.30 \mathrm{vol} \%$, and (d) $2.13 \mathrm{vol} \%$; adapted with permission from [78]. Copyright 2016 Elsevier.

One of the most important properties resulting from the presence of different predominant crystal facets is the photocatalytic activity that is connected with synergistic effects of different facets. The majority of studies reported that the photocatalytic activity of anatase crystals in the reaction of oxidation of organic compounds increased with an increase in the percentage of $\{001\}$ facets [122]. It has been proposed that the coexistence of different crystal facets, e.g., $\{101\}$ and $\{001\}$, might result in enhanced activity due to the synergistic effects between different facets. First, in the early studies, Ohno et al. reported the selective photodeposition of $\mathrm{Pt}$ and $\mathrm{PbO}_{2}$ particles on different facets of anatase and rutile crystals [73]. They postulated the existence of oxidation and reduction sites on $\{001\}$ and $\{101\}$ facets of anatase, and $\{011\}$ and $\{110\}$ facets of rutile, respectively. In the next research, Murakami et al. prepared DAP with a different aspect ratio between $\{001\}$ and $\{101\}$ facets (Figure 10a-c) [121]. They observed that the photocatalytic activity for the decomposition of acetaldehyde increased with an increase in the ratio of $\{101\} /\{001\}$ exposed crystal facets, which might indicate that the spatial separation of redox sites requires the existence of different types of crystal facets. In another study, Murakami et al. analyzed the dependence of photocatalytic activity on the aspect ratio of shape-controlled rutile nanorods (nanorods-1D nanostructure) [123]. The photocatalytic activity for acetaldehyde decomposition increased with the decreasing aspect ratio, which was not due 
to an increase in the number of adsorption sites, but rather to a more optimal ratio of the surface areas of oxidation and reduction sites (Figure 10d) [13]. The significant study confirming facet-dependent reactions has been performed by Tachikawa et al., in which selective oxidation on $\{001\}$ and reduction on $\{101\}$ facets have been proved by single-molecule imaging and kinetic analysis [126]. It should be pointed that both the selective deposition of metal/oxides (e.g., [73]) and an appearance of reaction products on selective facets (e.g., [126]) do not unequivocally confirm whether that particular reaction happens on that facet. For example, Kobayashi et al. has shown that the adsorption of noble metals depends on the surface charges and $\mathrm{pH}$ value of the reaction mixture [127].

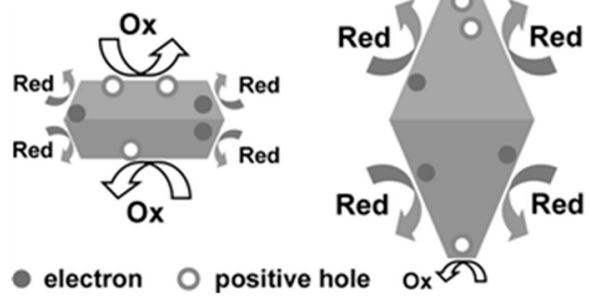

(a)

(b)

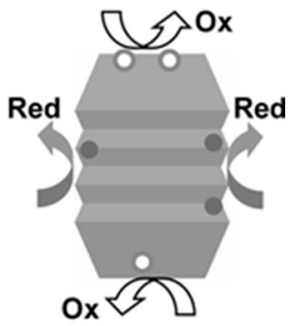

(c)

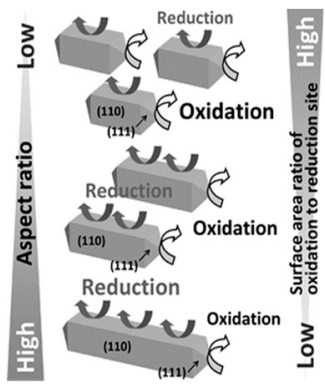

(d)

Figure 10. Schematic images of: $(\mathbf{a}-\mathbf{c})$ spatial separation of redox sites on anase with exposed crystal facets: (a) DAP with a larger surface area of oxidation sites and smaller area of reduction sites; (b) DAP with a smaller surface area of oxidation sites and larger area of reduction sites; (c) stacked-structure particle with larger surface area of both oxidation and reduction sites (adapted with permission from [121]; Copyright 2009 American Chemical Society); (d) dependence of aspect ratio of shaped-controlled rutile rods on the surface area ratio of oxidation to reduction sites (adapted with permission from [123]; Copyright 2011 American Chemical Society).

Although DAP particles have shown extremely high photocatalytic activity for both oxidation and reduction reactions (even higher than famous P25) [78], single-facet titania seems to be very attractive for mechanism study. For example, octahedral anatase particles (OAP) with eight $\{101\}$ facets showed very high photocatalytic activity for the oxidation of acetic acid [128,129]. Although, various reports (as also shown in this review) have claimed that faceted morphology was beneficial for photocatalytic activity, the direct proof was not presented until the study by Wei et al. [128,129]. In that study, OAP-containing samples, which differed only by morphology (same specific surface area, crystalline size, crystallinity, composition, etc.), i.e., the content of faceted particles in the final product, were prepared by hydrothermal-ultrasonic reaction. Indeed, it was proven that faceted morphology was beneficial, since with an increase in the content of faceted NPs, activity increased. Moreover, it was proposed that faceted NPs contained a larger content of shallow than deep electron traps (ETs), which facilitated electrons' migration instead of their permanent trapping, as assumed by photoacoustic spectroscopy (total content of ETs) and time-resolved microwave conductivity (electron mobility and lifetime; shallow ETs) [128].

The development of titania crystals with exposed facets provides an important platform for the rational design and production of efficient photocatalytic materials, including facet-dependent properties, and improving the performance in various applications. However, there are still unclear issues mostly regarding the mechanisms responsible for the unique photocatalytic properties of titania crystals with different facets. Despite that, it is thought that facet-dependent reaction selectivity is undoubtedly the most promising research direction in the further development of the efficient photocatalytic materials with high application potential. 


\subsection{One-Dimensional Titania}

Titania nanotubes, nanowires, 1D-oriented nanopores, and other 1D nanostructures (such as nanorods) have been extensively investigated for various applications, including solar cells, photocatalysis, batteries, filtration membranes, biomedical use, and as templates for the synthesis of other nanostructures [5,130-133]. Kasuga et al. were probably the first who prepared titania nanotubes (TNTs) by the chemical method [134,135], whereas Imai et al. obtained TNTs in porous alumina membrane by a deposition technique [136]. Since then, huge effort has been put toward the preparation of highly uniform and well-oriented TNTs. The most famous and popular is probably the preparation of TNTs by the electrochemical method, i.e., the anodization of titanium film, which was started by Grimes and Schmuki [137-139]. It should be pointed that different morphologies could be obtained by changing the anodization conditions, e.g., TNTs, as well as the mesoporous and nanoporous structures, as shown in Figure 11. Recently, a very interesting approach has been proposed by the Zaleska-Medynska group, i.e., the anodization of titanium alloys to prepare modified titania by a one-step reaction, e.g., $\mathrm{TiO}_{2} / \mathrm{Ag}_{2} \mathrm{O} / \mathrm{Ag}$ [132] and $\mathrm{TiO}_{2} / \mathrm{Cu}_{\mathrm{x}} \mathrm{O}_{\mathrm{y}}$ [131] from $\mathrm{Ti} / \mathrm{Ag}$ and $\mathrm{Ti} / \mathrm{Cu}$ alloys, respectively.

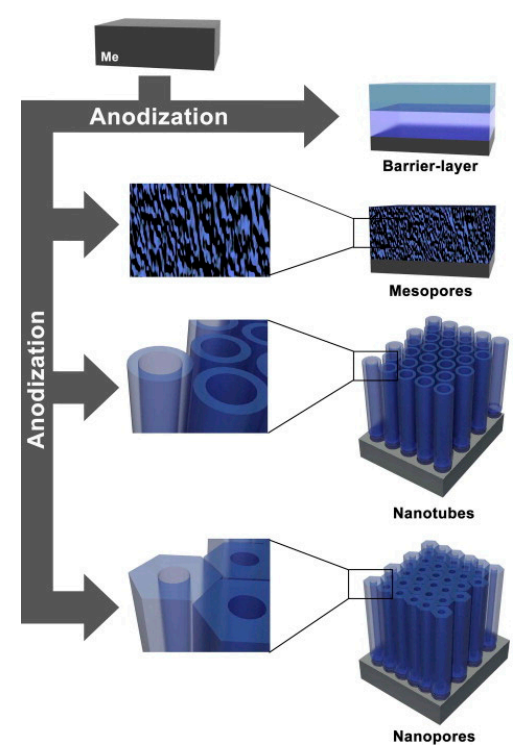

Figure 11. Different morphologies of metal oxides obtained by metal anodization, adapted with permission from [5]. Copyright 2013 Elsevier.

Although 1D nanostructures are very interesting, this chapter does not discuss them in detail since many review reports on TNTs (including also other 1D titania structures) have already been published, e.g., review papers on TNTs [5,140-143] and modified TNTs toward vis-response [144]. Here, only TNTs photonic crystals (PCs) are presented as novel and not well-explored titania nanostructures.

The designing of PCs, periodic optical nanostructures that affect the motion of photons, has been identified as an efficient method to enhance light harvesting, i.e., by using longer wavelengths (vis and IR). The uniqueness of PCs arises from the consistent spatial periodicity of the refractive index (n) in the well-ordered structure, which prevents the electromagnetic wave pathway at certain frequencies, resulting in the formation of the stop band and the photonic bandgap (PBG) [145]. The presence of PBG results in the formation of "slow photons" at both the red and blue edges of PBG, whereby the photons are scattered and reflected, causing the reduction of photons' group velocity $[145,146]$, which might be utilized for light absorption enhancement in titania-based photocatalysts.

Although PCs are usually designed as 3D nanostructures (e.g., opal and inverse opal), which are also discussed in this review (Section 3.4.2), TNT-PCs have been also reported $[147,148]$. TNT-PCs have been prepared by applying basic electrochemical anodization methods by alternating current and 
voltage, e.g., anodic oxidation [147] or two-step anodization [149-151]. The preparation techniques are critical for titania-based PCs, e.g., the roughness of the Ti foil before anodization has affected the light absorption properties, which are directly related to the periodic modulation properties $[147,150]$. The smoothness of the material surface after anodization would reflect the unique formation of PCs, which was observed by the appearance of various shiny colors (iridescence), as illustrated in Figure 12a [150]. TNT-PCs have been designed and explored in terms of the enhancement of the light harvesting. Many parameters of their preparation have been investigated, especially in consideration of the correlation between the photocatalytic activity and the PBG effects. For example, bamboo-like TNT-PC arrays with different nodes' lengths were designed by adjusting and maintaining the applied voltage, as shown in Figure 12b-c [147]. Interestingly, it was found that PBG was bathochromic shifted with the shortening of TNT. Moreover, Chiarello et al. reported that the PBG position was directly related to the diameter of TNT, the distance between each nanotube, and their thickness [148]. It was concluded that the PBG positions shifted to longer wavelengths with an increase in the diameter of TNTs, resulting in an enhanced photogeneration of hydrogen.

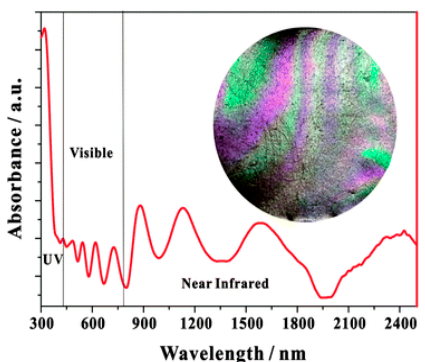

(a)

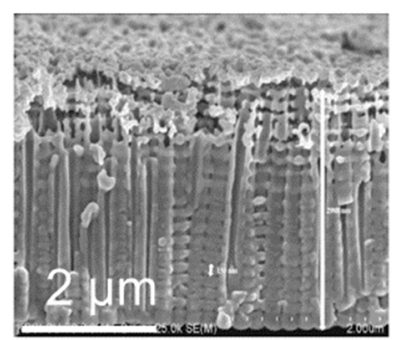

(b)

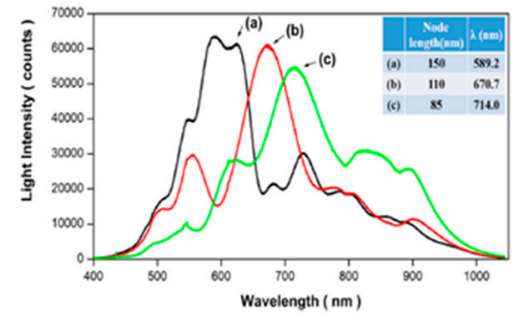

(c)

Figure 12. Characteristics of titania nanotubes photonic crystals (TNT-PCs): (a) UV-vis-NIR diffuse reflectance absorption spectra, the inset presents a digital photograph of the TNT-PCs; adapted with permission from [150]. Copyright 2014 Copyright Clearance Center, Inc.; (b) FE-SEM image and (c) diffraction spectrum of TNT-PCs arrays (prepared $\mathrm{TiO}_{2}$ with different node lengths); adapted with permission from [147]. Copyright 2017 Elsevier.

\subsection{Two-Dimensional Titania}

It is probable that 2D titania nanostructures, such as nanofilms, nanoplates, nanosheets, and nanobelts are the least examined for photocatalysis among all others, especially comparing with a huge number of studies on particulate titania (0D), titania nanotubes (1D), and 3D titania nanostructures. The investigations on 2D nanostructures have been intensively growing in recent years, especially for solar energy conversion, e.g., with $\mathrm{C}_{3} \mathrm{~N}_{4}, \mathrm{MoS}_{2}$, and graphene-like materials (graphene, graphene oxide, reduced graphene oxide), due to their relatively large surface area, fast transfer of charge carriers to the photocatalyst surface, and thus low recombination of charge carriers, and thus high photocatalytic activity. Although various materials have been prepared as 2D nanostructures, 2D titania nanostructures have been rarely prepared and reported. Of course, films of titania have been intensively studied and commercially applied (self-cleaning, antifogging, and antiseptic materials), but these are not 2D "nano" structures.

Although well-organized titania nanostructures might be easily obtained by a convenient hydrothermal method, such as nanowires (1D), nanotubes (1D), and faceted NPs (0D), other methods are used for the preparation of 2D titania nanostructures since titania films are usually deposited on some supports, such as glass, polyvinyl chloride, and quartz. Therefore, chemical vapor deposition (CVD) [152], plasma-enhanced chemical vapor deposition (PECVD) [153], dc-sputtering [154], anodization (exemplary shown in Figure 11 as "mesopores") [155] and successive-ionic-layer-adsorption-andreaction (SILAR) [156] methods have been proposed for the preparation of 2D titania photocatalysts. 
However, hydrothermal methods have been also used for the preparation of titania nanoplates (shown in Figure 13) for application as sensors to detect toxic gases [157].

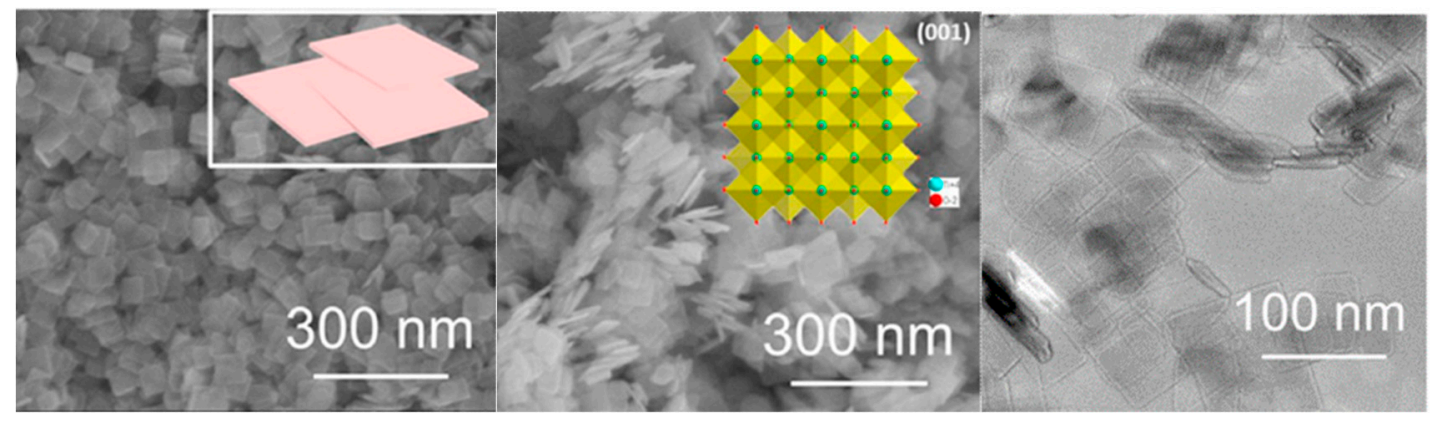

(a)

(b)

(c)

Figure 13. Electron microscopy images of titania nanoplates: (a,b) SEM and (c) TEM images; insets presenting (a) nanoplate shapes; (b) a crystal model of single crystalline anatase; adapted with permission from (after formatting) [157]. Copyright 2016 Elsevier.

An interesting study has been conducted by Deng et al. for amorphous titania nanofilms, prepared by the SILAR method from titanium isopropoxide [152]. Surprisingly, the authors obtained higher activity for formaldehyde mineralization on amorphous titania film than that on anatase film. It was concluded that abundant hydroxyl groups and a large surface area, allowing an efficient adsorption of formaldehyde, were responsible for its high photocatalytic activity. Moreover, it was proposed that rapid electron transfer along $\mathrm{CB}\left(>\mathrm{Ti}^{\mathrm{III}} \mathrm{OH}\right)$-which allocated terminal hydroxyl groups and minimized transfer length from bulk to surface (nanofilm layer) - resulted in a hindered recombination of charge carriers.

It should be pointed that similar to magnetic core-shell NPs (Section 3.1.1.) and TNT (1D), 2D titania materials have been mainly designed for possible commercial application, considering their continuous use. Therefore, 2D titania nanostructures have been tested for gas and liquid phases' purification, e.g., (i) formaldehyde mineralization in the gas phase [152], (ii) the degradation of 2-(phosphomethylamino)acetic acid and methylene blue, and the inactivation of Micrococcus lutes bacteria in liquid phase [156]. All these studies concluded that titania nanofilms were highly recommended for commercial applications, e.g., using films inside photocatalytic reactors (covering of wall or lamp surfaces) for environmental remediation and disinfection purposes.

The various composites of titania with 2D nanostructures of other materials (titania/graphene, titania/graphene oxide, titania/reduced graphene oxide, and titania/ $C_{3} N_{4}$ ) have been also investigated. Although these 2D nanostructures have been indicated as probably the most prospective for commercial applications, they are not discussed in this review, since well-written review papers have already been published, e.g., [158,159].

\subsection{Three-Dimensional Titania}

Three-dimensional titania structures, e.g., mesoporous structures, aerogels, opals, and inverse opals have been designed and prepared for two main purposes, i.e., possible commercial applications (to avoid the expensive recovery of particulate titania) and for mechanism study. Here, three kinds of 3D titania structures are shortly presented, i.e., aerogels, inverse opal photonic crystals (IO-PCs), and mesocrystals.

\subsubsection{Titania Aerogels}

Titania aerogels are very interesting nano/microstructures, due to their low density, porosity, high pore volume, and large specific surface area [160-163]. Although they are commonly composed of NPs of titania, the resultant aerogel structure is much larger, and thus titania aerogels might be 
classified as 3D structures. Titania aerogels has been proposed as efficient photocatalysts with activities similar to those by P25 [162]. An interesting approach was used by Pietron and coworkers to study the mechanism of plasmonic photocatalysis. Plasmonic photocatalysis, heterogeneous photocatalysis under vis irradiation on a wide bandgap semiconductor (usually titania) modified with plasmonic NPs, such as gold, silver, and copper (metals with localized surface plasmon resonance at vis range of solar spectrum), has been a hot topic recently [164]. Although plasmonic photocatalysts showed activity at broad irradiation ranges for various reactions, the mechanism has not been clarified yet. Two main mechanisms of plasmonic photocatalysis have been considered, i.e., energy and charge (usually electron) transfer. Accordingly, two kinds of titania aerogels have been prepared, i.e., with 5-nm gold NPs incorporated inside the 3D titania aerogel network (3D Au- $\left.\mathrm{TiO}_{2}\right)$ or not $\left(\mathrm{Au} / \mathrm{TiO}_{2}\right)$, as shown in Figure $14[165,166]$. Interestingly, it was found that $3 \mathrm{D} \mathrm{Au}-\mathrm{TiO}_{2}$ possessed much higher activity than that prepared by the simple deposition of gold on the surface of titania aerogel $\left(\mathrm{Au} / \mathrm{TiO}_{2}\right)$, suggesting that direct contact (interface) between gold and titania was crucial. Although authors discussed the possibilities of both mechanisms, the key factor of morphology (gold position inside the aerogel, resulting in a large interface of gold-titania) could suggest that the charge transfer mechanism, i.e., "hot" electron transfer from gold to the CB of titania, has been the predominant one in the case of gold-titania plasmonic photocatalysts under vis irradiation.

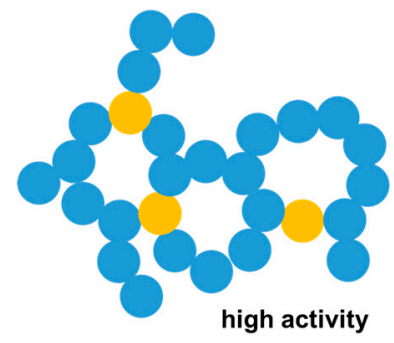

(a)

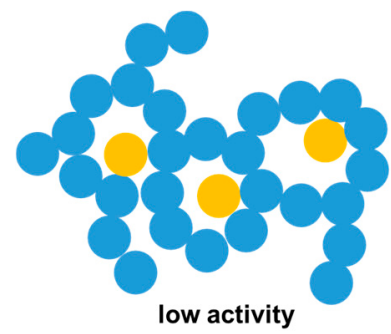

(b)

Figure 14. Schemes showing titania aerogels (blue) with gold NPs (yellow dots): (a) incorporated inside the titania network $\left(3 \mathrm{D} \mathrm{Au}-\mathrm{TiO}_{2}\right)$; and $(\mathbf{b})$ deposited on the surface of titania aerogels $\left.(\mathrm{Au} / \mathrm{TiO})_{2}\right)$; drawn based on references [165,166].

\subsubsection{Inverse Opal Photonic Crystals (IO-PCs)}

The 3D titania PCs (1D PCs in Section 3.2) have been intensively studied in recent years, due to the many advantages of the obtained meso/microporous structures, such as efficient mass transport, large surface area, and tunable porosity [167-169]. Inverse opal PCs (IO-PCs) comprise the exact replica structure obtained by using the opal as a template, as shown in Figure 15a. IO-PCs structures are usually obtained after undergoing three-step synthesis, namely (1) the self-assembly of monodispersed colloidal particles to form an opal structure, (2) infiltration of the precursor (here titania precursor), and finally (3) the removal of opal, which acts as a sacrificial template for the IO structures. All these steps are critical and need to be carried out by considering the optimum synthesis conditions to prevent defects and cracks, which could affect the final quality of the titania IO-PCs [170-172]. Different types of colloidal particles, e.g., silica $\left(\mathrm{SiO}_{2}\right)$, polystyrene (PS), and polymethyl methacrylate (PMMA) have been used for IO formation. It should be pointed that the monodispersity of particles $(<5 \%$ variation in the size/shape $[171,173]$ ) is necessary to form opal. The variety in the sizes and shapes of particles would result in disordered arrangement, which affects the quality of opal and IO structures. In contrast, some reports have claimed that polydispersed large $\mathrm{SiO}_{2}$ particles could also form close-packed arrays under negative pressure $[174,175]$. However, it should be pointed that for optical applications of opal and IO-PCs, monodispersed colloidal particles are the most recommended. The assembly process might be carried out by a few methods, i.e., vertical capillary deposition [176-178], spin coating [179], gravitational sedimentation [180], and sedimentation assisted by centrifugation [181]. Post-thermal 
treatment has been suggested as a good method to provide better mechanical stability and to form a neck between the particles [182]. Probably, the most difficult step is to obtain the stable IO structure, i.e., efficient titania infiltration/impregnation. Various approaches have been proposed for the IO structure, including drop casting and capillary force $[178,183]$, vacuum infiltration $[178,183]$, atomic layer deposition (ALD) [184,185], spin-coating [186], and chemical vapor deposition (CVD) [187]. Finally, the crystallization of titania is performed, which results in $15 \%-30 \%$ shrinkage of the structure, causing the pore size reduction [188-191]. The final step is to remove the template, which might be done by calcination (for polymers) $[177,178,183,192]$ and chemical treatment with a concentrated base, sodium hydroxide, or hydrofluoric acid (for silica) [193]. In order to enhance light harvesting and/or the resultant properties and photocatalytic activities, modifications with metals, e.g., gold [179,191], silver [193], nickel [186,194], and semiconductors, e.g., cadmium selenide, cadmium sulfide quantum dots (QDs) [184,195], and zinc oxide NPs [196], have been proposed.

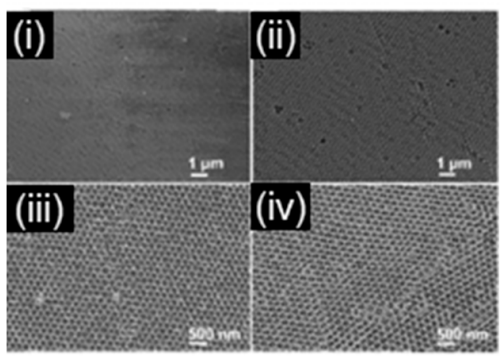

(a)

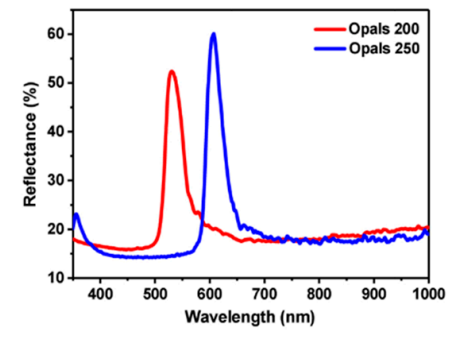

(b)

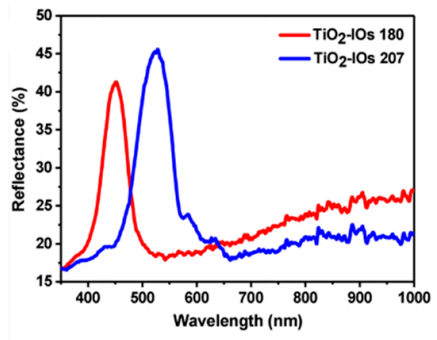

(c)

Figure 15. Characteristics of opal (polystyrene (PS) spheres) and inverse opal (IO) titania structures: (a) FESEM images of PS opal with: (i) 200-nm and (ii) 250-nm sphere sizes, and replicated titania IO films with: (iii) 180-nm and (iv) 207-nm voids; reflection spectra of: (b) PS templates and (c) titania IOs; adapted with permission from [178]. Copyright 2019 Creative Commons Attribution.

The PBG of IO-PCs could be tuned by various approaches, including the nanovoid diameter (as shown in Figure 15b,c) and the angle of the light irradiation. It was found that the PBG was hypsochromic shifted with an increase in the calcination temperature, resulting in a decrease in the nanovoids' diameter [190]. The photocatalytic activities of IO-PCs have been investigated under both UV [149,197] and vis [186,191,193] irradiation, as summarized in Table 3. The most important property of IO structures is tunable nanovoid dimensions, resulting in the scattering and reflection of light. Many reports have reported how the nanovoid diameter could be related to the PBG, and thus the resultant photocatalytic activity. For example, the reduced velocity of photons and hindered recombination of charge carriers were the most evident for titania $\mathrm{IO}$ with the largest voids of $610 \mathrm{~nm}$ [198]. In contrast, the smallest voids in CdS-QD-sensitized titania IO gave the highest photoelectrochemical enhancements [184]. Hence, although the nanovoid diameter plays a vital role in PBG, the resultant photocatalytic activity might differ depending on various factors, including the specific surface area, porosity, and various co-modifications.

Apart from the nanovoid diameter, the slow photon effect, affected by the angle of irradiation source $[183,188]$, would influence the overall photocatalytic activity. For example, PBG was blue-shifted with an increase in the irradiation angle $[183,188,190]$. Kim and Choi found that the degradation of stearic acid on IO with $247-\mathrm{nm}$ voids was two times higher under irradiation at $40^{\circ}$ than at different irradiation angles [147]. In contrast, Jovic et al. did not find the direct correlation between the voids' sizes and the photocatalytic activity [183]. However, the overlapping between the bandgap of titania and the red-edge wavelength of PBG gave rise to the slow photon effect, and thus enhanced activity $[183,188]$. Similar correlation was found by Rahul et al. on the overlapping of the red-edge of PBG and the bandgap of titania by titania IO film with 215-nm voids [199], resulting in the complete decomposition of RhB dye in only $2 \mathrm{~min}$. The importance of IO structures was confirmed 
in research on the comparison between original titania IOs and slightly destroyed structures, e.g., by ultrasonication [197] and grinding [189], where the undestroyed IOs structure was the most efficient.

Moreover, heterostructure engineering, e.g., the coupling of titania IO-PCs with other semiconductors and modifications with noble metals, has been shown to have a positive effect on the overall activity. Although various reasons have been proposed, including the separation of charge carriers, enhanced light harvesting, synergy, and a higher specific surface area, it is still unclear what properties are the most recommended for specific application. Considering photocatalytic reactions, it seems that the modification of titania IO-PCs with NPs/composites with the ability to absorb photons at or near PBG would result in photocatalytic materials of extremely high efficiency. Moreover, such materials might be very helpful for mechanism study, e.g., plasmonic photocatalysis (as discussed in Section 3.4.1). For example, the preparation of titania IO containing gold NPs (in each void) of the sizes corresponding to LSPR (localized surface plasmon resonance) of gold, the same or different to PBG of titania IO $\left(\lambda_{\mathrm{LSPR}}=\lambda_{\mathrm{PBG}}, \lambda_{\mathrm{LSPR}}>\lambda_{\mathrm{PBG}}\right.$ and $\left.\lambda_{\mathrm{LSPR}}<\lambda_{\mathrm{PBG}}\right)$, might enable finding (i) the direct correlation between the photoresponse and the properties (e.g., by action spectrum analysis), (ii) the difference between electron and energy transfer mechanism, and (iii) the key factor of photocatalytic activity.

Table 3. Titania IO-PCs: preparation method, applications and important findings.

\begin{tabular}{|c|c|c|c|c|c|}
\hline IO-PCs & Opal/Template & $\begin{array}{l}\text { Infiltration } \\
\text { Method }\end{array}$ & Photocatalytic Tests & Findings & Ref. \\
\hline IO film & PMMA & $\mathrm{CF}$ & SA degr. at $400 \mathrm{~nm}\left(0-50^{\circ}\right)$ & $\begin{array}{l}P B G_{\max }=490 \mathrm{~nm} \\
\text { most effective at } 40^{\circ}\end{array}$ & [192] \\
\hline IO films & PS & $\mathrm{CF}$ & $\begin{array}{c}\text { MB degr.; } \lambda=450 \mathrm{~nm} \\
\mathrm{CH}_{3} \mathrm{CHO}(\mathrm{g}) \text { degr. at } \\
365 \mathrm{~nm}\end{array}$ & high activity & [188] \\
\hline IO films & PS & ALD & IO as photoanode (DSSCs) & PCE of $2.22 \%$ & [185] \\
\hline IO films & PS & CF & RhB degr. at $250800 \mathrm{~nm}$ & $95 \%$ degr. at $0^{\circ}$ & [190] \\
\hline IO films & PS & SW & RhB degr. $\lambda=320-800 \mathrm{~nm}$ & VSDA & [200] \\
\hline LP-IO film & PMMA & $\mathrm{CF}$ & MB degr. at $400 \mathrm{~nm}$ & high film stability & [177] \\
\hline IO film with LC & PS & SW-vacuum & 0 & $\begin{array}{c}\mathrm{PBG}_{\max }=452 \text { and } 528 \mathrm{~nm} \\
\text { switchable PCs }\end{array}$ & [178] \\
\hline $\begin{array}{l}\text { IO powd. and } \\
\text { films }\end{array}$ & PMMA & $\begin{array}{l}\text { vacuum } \\
\mathrm{CF}\end{array}$ & $\begin{array}{l}\text { ethanol }(\mathrm{g}) \text { oxidation } \\
\lambda_{\max }=365 \mathrm{~nm}\end{array}$ & VSDA & [183] \\
\hline IO powd. & PS & CF & MB degr. $\lambda>400 \mathrm{~nm}$ & VSDA & [198] \\
\hline IO powd. & PMMA & vacuum & $\begin{array}{c}\text { phenol degr. } \\
\lambda_{\max }=365 \mathrm{~nm}\end{array}$ & VSDA & [189] \\
\hline $\mathrm{Au} / \mathrm{IO}$ powd. & PMMA & $\mathrm{CF}$ & $\begin{array}{l}\text { water splitting }\left(\mathrm{H}_{2}\right) \\
\text { under UV and solar }\end{array}$ & $\mathrm{Au} / \mathrm{IO}-\mathrm{H}_{2}$ generation & [201] \\
\hline $\mathrm{Au} / \mathrm{IO}$ film & PS & $\mathrm{CF}$ & PEC water splitting & $\mathrm{Au} / \mathrm{st}-\mathrm{IO}$ with high PD & [179] \\
\hline $\mathrm{Ag} / \mathrm{IO}$ film & $\mathrm{SiO}_{2}$ & dip coating & $\begin{array}{l}\text { MB degr. } \lambda=254 \mathrm{~nm} \\
\text { and } \lambda=400-760 \mathrm{~nm}\end{array}$ & Ag-enhanced activity & [193] \\
\hline $\mathrm{CdSe} / \mathrm{IO}$ & PS & dip coating & $\begin{array}{c}\text { SERS for MO } \\
\text { PEC measurement }\end{array}$ & $\begin{array}{c}\text { CdSe-IO as SERS substrate } \\
\text { with a high sensitivity }\end{array}$ & [195] \\
\hline CdS/IO film & PS & ALD & PEC; solar & CdS/IO with high PD & [184] \\
\hline $\begin{array}{c}\mathrm{Ni} / \\
\mathrm{IO} \text { film }\end{array}$ & PS & spin coating & $\begin{array}{c}\text { SERS for 4-MBA } \\
\text { MO degr. } \lambda>400 \mathrm{~nm}\end{array}$ & $\begin{array}{l}\mathrm{Ni} / \mathrm{IO} \text { for SERS with high } \\
\text { detection ability }\end{array}$ & [186] \\
\hline BIO/Ni film & PS & SW and CF & CO evolution; $\lambda>400 \mathrm{~nm}$ & high rate of $\mathrm{CO}$ generation & [194] \\
\hline $\mathrm{Au} / \mathrm{F} / \mathrm{IO}$ film & PS & SW and CF & $\mathrm{H}_{2}$ evolution; $\lambda>400 \mathrm{~nm}$ & high rate of $\mathrm{H}_{2}$ generation & [202] \\
\hline$(\mathrm{N}-\mathrm{F}) / \mathrm{IO}$ film & PS & SW aided by $\mathrm{CF}$ & RhB degr.; solar & $\begin{array}{c}\mathrm{PBG}_{\max }=336 \text { and } 850 \mathrm{~nm} \\
100 \% \text { RhB degr. }\end{array}$ & [199] \\
\hline $\mathrm{IO} / \mathrm{Au}$ & PS & LPD & 2,4-DCP degr.; $\lambda>420 \mathrm{~nm}$ & VSDA & [191] \\
\hline $\mathrm{H} / \mathrm{IO}$ powder & PS & forced impregn. & $\mathrm{H}_{2}$ evolution; solar & VSDA & [203] \\
\hline $\mathrm{ZnO} / \mathrm{IO}$ film & PS & SW & MO degr.; $\lambda=320-800 \mathrm{~nm}$ & VSDA & [196] \\
\hline \multicolumn{6}{|c|}{ 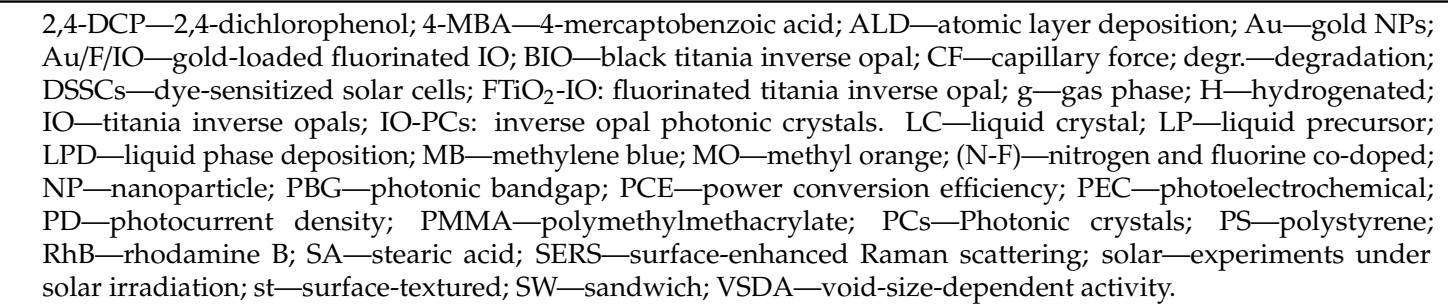 } \\
\hline
\end{tabular}




\subsubsection{Titania Mesocrystals}

Mesocrystals are a quite new and fascinating nanostructure, which is composed of aligned nanocrystals [204-206]. The mesocrystal structure might be synthesized from the primary nanocrystals by self-assembly-based crystallization (non-classical crystallization, as shown in Figure 16 [204]) and a template method (e.g., polyethylene template [207]). For example, Wu et al. confirmed that rutile titania mesocrystals have been formed by the rapid crystallization by particle attachment (CPA), i.e., non-classical crystallization [208]. The mesocrystal structure has been considered as a potential functional material, combining both the properties of NPs (e.g., the shape, specific surface area, photocatalytic activity) and "advanced super structure" (e.g., increased crystallinity, improved charge transfer). Titania mesocrystals have been proposed for various applications, e.g., photocatalytic purification, solar energy conversion, and energy storage. Thanks to their 3D structure, titania mesocrystals can be also used for mechanism clarifications, such as titania aerogels (Section 3.4.1). For example, Bian et al. prepared titania mesocrystals with gold deposited either on basal or lateral surfaces of mesocrystals and on titania NPs [209]. They found that the deposition of gold on the basal structure resulted in enhanced photocatalytic activity, since "hot" electrons could easily migrate through the titania nanocrystal network to the edges of the plate-like mesocrystals, where they were temporary stored for further reactions. Due to this anisotropic electron flow, which hindered the recombination of charge carriers (back electron transfer to gold $\left(\mathrm{Au} \rightarrow \mathrm{TiO}_{2} \rightarrow \mathrm{Au}\right.$ ) has been considered as the main reason for the low activity of plasmonic photocatalysts), this structure was characterized by long electron lifetime, and thus enhanced photocatalytic activity.

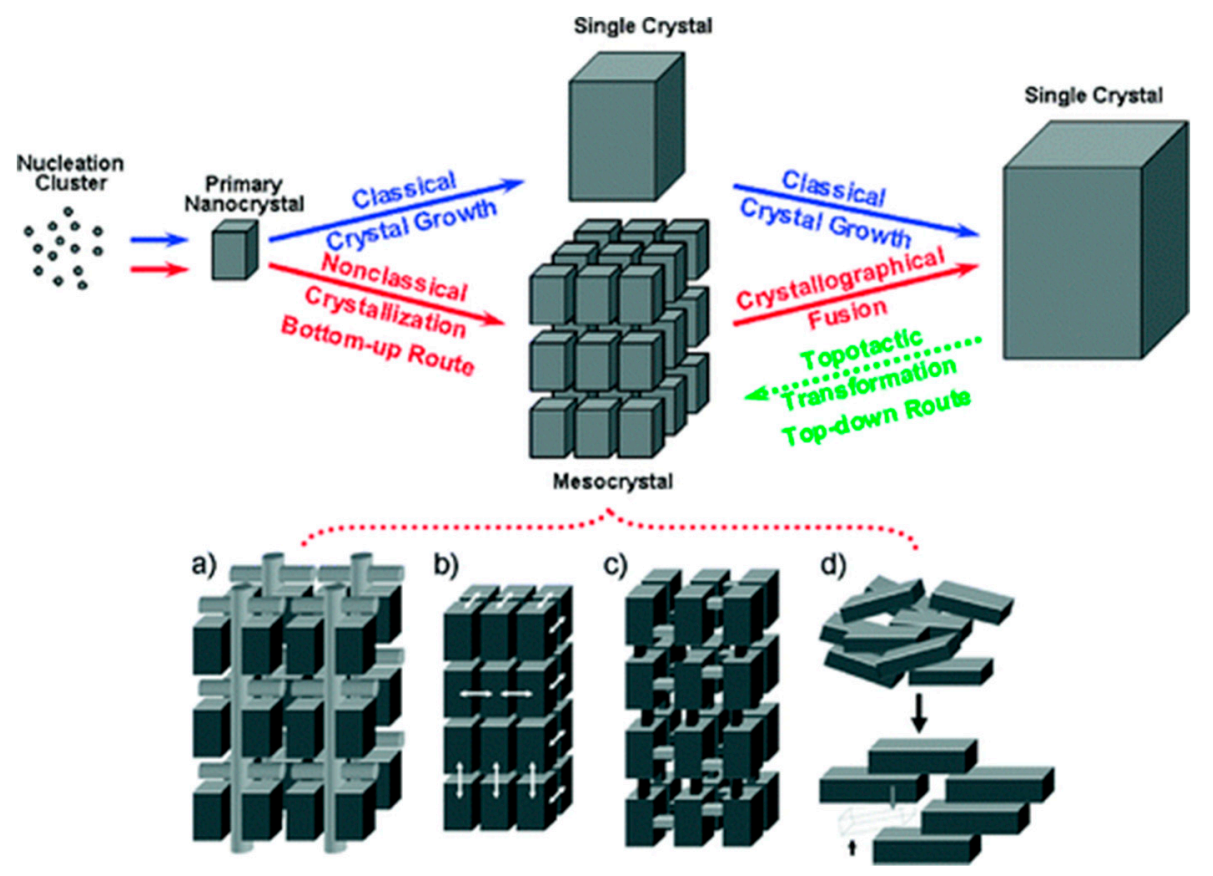

Figure 16. Schematic drawings of mesocrystal formation (red route) and classical crystal growth (blue route) [204]. Copyright 2012 American Chemical Society.

\section{Summary and Conclusions}

A large number of studies on the crystalline composition- and morphology-governed photocatalytic activity of titania-based materials have been extensively carried out until now. The advances performed in research in this field during the last decade are immensely significant and noteworthy. In this review, the state-of-the-art has been presented on the correlation between the structural/morphological aspects and $\mathrm{TiO}_{2}$ photocatalytic activity with a special emphasis directed on 
the new trends in the architecture design of titania and titania-based photocatalysts, such as faceted titania, inverse-opal structures, aerogels and core-shells.

First, the role of titania polymorphs for the photocatalytic activity has been discussed, including the exceptional importance of mixed-phase titania photocatalysts. In the literature, one can find many attempts to obtain such mixed-phase materials. They are applicable to the different types of photocatalytic reactions, such as the oxidation of organic pollutants, hydrogen generation, or $\mathrm{CO}_{2}$ conversion. Among them, a special role is played by commercially available P25, which is recognized as a reference material that is applied in various types of reactions due to its unique photocatalytic efficiencies. However, an explicit explanation of the phenomenon of the "synergistic effect" responsible for the high activity of mixed-phase $\mathrm{TiO}_{2}$ materials is still a challenge.

In the further part of the review, plenty of nanostructured titania materials have been discussed. The formal division of these materials into zero-, one-, two-, and three-dimensional structures has been performed and shortly summarized in Table 4. Among 0D titania nanostructures, the preparation of core-shell composites gives the possibility of incorporating additional functions to the photocatalytic titania-based materials, such as magnetic properties resulting from the presence of magnetic core, and thus enabling easy separation in the magnetic field. In the case of another 0D-structural approach: faceted titania particles, the role of different crystal facets, and the synergistic effect between them have been emphasized to clarify the high application potential of these materials, including the concept of facet-dependent reaction selectivity.

Table 4. Structure, synthesis, and exemplary applications of titania materials with different morphology. CVD: chemical vapor deposition, PECVD: plasma-enhanced chemical vapor deposition, SILAR: successive-ionic-layer-adsorption-and-reaction.

\begin{tabular}{|c|c|c|c|c|c|}
\hline Dimension & Morphology & Preparation & Schemes & Applications & References \\
\hline $0 \mathrm{D}$ & $\begin{array}{l}\text { nanorice, } \\
\text { core-shells, } \\
\text { NPs faceted } \\
\text { particles }\end{array}$ & $\begin{array}{l}\text { sol-gel, } \\
\text { hydrothermal, } \\
\text { solvothermal, } \\
\text { gas-phase }\end{array}$ & & $\begin{array}{l}\text { antifogging, } \\
\text { antiseptic, } \\
\text { self-cleaning } \\
\text { surfaces, } \\
\text { photocatalysts }\end{array}$ & {$[78,112-122]$} \\
\hline $1 \mathrm{D}$ & $\begin{array}{c}\text { nanotubes, } \\
\text { nanowires, } \\
\text { nanorods }\end{array}$ & $\begin{array}{l}\text { anodization, } \\
\text { hydrothermal }\end{array}$ & & $\begin{array}{c}\text { solar cells, } \\
\text { batteries, } \\
\text { photocatalysts }\end{array}$ & [131-145] \\
\hline $2 \mathrm{D}$ & $\begin{array}{l}\text { nanoplates, } \\
\text { nanosheets, } \\
\text { nanolayers }\end{array}$ & $\begin{array}{l}\text { hydrothermal, } \\
\text { solvothermal, } \\
\text { CVD, PECVD, } \\
\text { SILAR }\end{array}$ & & $\begin{array}{c}\text { sensors for } \\
\text { toxic gas, } \\
\text { photocatalysts, } \\
\text { solar cells }\end{array}$ & {$[150-155,210]$} \\
\hline $3 \mathrm{D}$ & $\begin{array}{c}\text { aerogels, } \\
\text { inverse-opal } \\
\text { photonic } \\
\text { crystals, } \\
\text { mesocrystals }\end{array}$ & $\begin{array}{c}\text { Sol-gel, } \\
\text { template, } \\
\text { self-assembling, } \\
\text { hydrothermal }\end{array}$ & & $\begin{array}{l}\text { photocatalysts, } \\
\text { solar cells, } \\
\text { energy storage, }\end{array}$ & $\begin{array}{l}{[158-161],} \\
{[163,164],} \\
{[168-170],} \\
{[202-204]}\end{array}$ \\
\hline
\end{tabular}

In the discussion of 1D and 3D nanostructures, the exceptional role of photonic nanocrystals in the form of titania nanotubes and 3D structures has been shown. The exceptional property of IO-PCs is the possibility of PBG tuning. Therefore, the modification of titania IO-PCs with other NPs (e.g., gold) or composites might introduce the ability of photoabsorption at or near the photonic bandgap, resulting in exceptionally efficient photocatalytic materials. Other promising 3D nanostructures can be recognized as titania aerogels with unique properties, such as low porosity, high pore volume, and large specific surface area, which are especially efficient as plasmonic photocatalysts with high visible-light activity. Two-dimensional (2D) structures (e.g., nanofilms, nanoplates, nanosheets), which 
are less often described in the literature, have been also considered in this review. Their application potential can be connected with environmental remediation and disinfection purposes (nanofilms).

The proper selection of the type of titania nanostructure together with considering the heterostructure engineering (e.g., coupling) or titania modification is the complex strategy to design the photocatalytic materials, which are oriented for the specific reaction systems. Despite the wide discussion about the mechanisms and reasons responsible for the specific properties of different morphological titania structures, it is still unclear which properties are the most recommended for the specified application. However, this review might be useful for the architecture design of novel titania-based nanomaterials for broad and diverse applications.

Funding: This research was financially supported by "Yugo-Sohatsu Kenkyu" for an Integrated Research Consortium on Chemical Sciences (IRCCS) project from Ministry of Education and Culture, Sport, Science and Technology-Japan (MEXT), and National Natural Science Foundation of China (NSFC; contract No. 51802087).

Conflicts of Interest: The authors declare no conflict of interest.

\section{Abbreviations}

OD—zero-dimensional; 1D—one-dimensional; 2D—two-dimensional; 3D—three-dimensional; CB-conduction band; CVD—chemical vapor deposition; DAP_decahedral anatase particles; DRS—diffuse reflection spectrum; DSSCs—dye-sensitized solar cells; EISA—evaporation-induced self-assembly; EPR—electron spin resonance spectroscopy; ET(s)—electron trap(s); (g)—gas phase; IO_inverse opal; IO-PCs—inverse opal photonic crystals; IPCT-interparticle charge transfer; NP(s)—nanoparticle(s); OAP-octahedral anatase particles; P25-commercial titania with high photocatalytic activity from Evonik (known also as Degussa P25 and Aeroxide P25); PBG—photonic bandgap; PC(s)—photonic crystal(s); PECVD—plasma enhanced chemical vapor deposition; PMMA — polymethyl methacrylate; PS—polystyrene; QD(s)—quantum dot(s); ROS-reactive oxygen species; SILAR - successive-ionic-layer-adsorption-and-reaction; VB-valence band; TBu-titanium butoxide; TIP—titanium isopropoxide; TNT(s)—titania nanotube(s); TNT-PCs—titania nanotube-photonic crystals; vis-visible light.

\section{References}

1. El Goresy, A.; Dubrovinsky, L.; Gillet, P.; Graup, G.; Chen, M. Akaogiite: An ultra-dense polymorph of $\mathrm{TiO}_{2}$ with the baddeleyite-type structure, in shocked garnet gneiss from the Ries Crater, Germany. Am. Miner. 2010, 95, 892-895. [CrossRef]

2. Smalley, R.E. Nanotechnology, Energy and People; MIT Forum: River Oaks, TX, USA, 2003.

3. Hashimoto, K.; Irie, H.; Fujishima, A. $\mathrm{TiO}_{2}$ photocatalysis: A historical overview and future prospects. Jpn. J. Appl. Phys. 2005, 44, 8269-8285. [CrossRef]

4. Zaleska, A. Doped-TiO 2 : A review. Recent Pat. Eng. 2008, 2, 157-164. [CrossRef]

5. Kowalski, D.; Kim, D.; Schmuki, P. TiO 2 nanotubes, nanochannels and mesosponge: Self-organized formation and applications. Nano Today 2013, 8, 235-264. [CrossRef]

6. Tsang, C.H.A.; Li, K.; Zeng, Y.X.; Zhao, W.; Zhang, T.; Zhan, Y.J.; Xie, R.J.; Leung, D.Y.C.; Huang, H.B. Titanium oxide based photocatalytic materials development and their role of in the air pollutants degradation: Overview and forecast. Environ. Int. 2019, 125, 200-228. [CrossRef]

7. Kandiel, T.A.; Feldhoff, A.; Robben, L.; Dillert, R.; Bahnemann, D.W. Tailored titanium dioxide nanomaterials: Anatase nanoparticles and brookite nanorods as highly active photocatalysts. Chem. Mater. 2010, 22, 2050-2060. [CrossRef]

8. Di Paola, A.; Bellardita, M.; Palmisano, L. Brookite, the least known $\mathrm{TiO}_{2}$ photocatalyst. Catalysts 2013, 3 , 36-73. [CrossRef]

9. Prieto-Mahaney, O.O.; Murakami, N.; Abe, R.; Ohtani, B. Correlation between photocatalytic activities and structural and physical properties of titanium(IV) oxide powders. Chem. Lett. 2009, 38, 238-239. [CrossRef]

10. Oyama, T.; Iimura, Y.; Takeuchi, K.; Ishii, T. Synthesis of rutile and anatase $\mathrm{TiO}_{2}$ fine particles by laser-ignited vapour-phase reaction. J. Mater. Sci. Lett. 1996, 15, 594-596. [CrossRef]

11. Ohno, T.; Tokieda, K.; Higashida, S.; Matsumura, M. Synergism between rutile and anatase $\mathrm{TiO}_{2}$ particles in photocatalytic oxidation of naphthalene. Appl. Catal. A Gen. 2003, 244, 383-391. [CrossRef]

12. Murabayashi, M.; Itoh, K.; Furushima, H.; Chen, D. Photocatalytic degradation of chloroform with rutile-anatase mixed $\mathrm{TiO}_{2}$ powder. Denki Kagaku 1991, 59, 524-525. 
13. Hatayama, F.; Ohno, T.; Maruoka, T.; Ono, T.; Miyata, H. Structure and Acidity of Vanadium-Oxide Layered on Titania (Anatase and Rutile). J. Chem. Soc. Faraday Trans. 1991, 87, 2629-2633. [CrossRef]

14. Augustynski, J. The role of the surface intermediates in the photoelectrochemical behavior of anatase and rutile $\mathrm{TiO}_{2}$. Electrochim. Acta 1993, 38, 43-46. [CrossRef]

15. Rao, M.V.; Rajeshwar, K.; Verneker, V.R.P.; DuBow, J. Photosynthetic production of hydrogen and hydrogen peroxide on semiconducting oxide grains in aqueous solutions. J. Phys. Chem. 1980, 84, 1987-1991. [CrossRef]

16. Gratzel, M.; Rotzinger, F.P. The Influence of the crystal-lattice structure on the conduction-band energy of oxides of titanium(IV). Chem. Phys. Lett. 1985, 118, 474-477. [CrossRef]

17. Yang, H.Y.; Zhu, S.K.; Pan, N. Studying the mechanisms of titanium dioxide as ultraviolet-blocking additive for films and fabrics by an improved scheme. J. Appl. Polym. Sci. 2004, 92, 3201-3210. [CrossRef]

18. Luo, Z.; Poyraz, A.S.; Kuo, C.H.; Miao, R.; Meng, Y.T.; Chen, S.Y.; Jiang, T.; Wenos, C.; Suib, S.L. Crystalline mixed phase (anatase/rutile) mesoporous titanium dioxides for visible light photocatalytic activity. Chem. Mater. 2015, 27, 6-17. [CrossRef]

19. Kumar, S.; Mishra, D.K.; Sobral, A.J.F.N.; Kohl, J. $\mathrm{CO}_{2}$ adsorption and conversion of epoxides catalyzed by inexpensive and active mesoporous structured mixed-phase (anatase/brookite) $\mathrm{TiO}_{2}$. J. $\mathrm{CO}_{2}$ Util. 2019, 34, 386-394. [CrossRef]

20. Mutuma, B.K.; Shao, G.N.; Kim, W.D.; Kim, H.T. Sol-gel synthesis of mesoporous anatase-brookite and anatase-brookite-rutile $\mathrm{TiO}_{2}$ nanoparticles and their photocatalytic properties. J. Colloid Interface Sci. 2015, 442, 1-7. [CrossRef]

21. Loryuenyong, V.; Buasri, A.; Srilachai, C.; Srimuang, H. The synthesis of microporous and mesoporous titania with high specific surface area using sol-gel method and activated carbon templates. Mater. Lett. 2012, 87, 47-50. [CrossRef]

22. Yu, J.C.; Yu, J.G.; Ho, W.K.; Zhang, L.Z. Preparation of highly photocatalytic active nano-sized $\mathrm{TiO}_{2}$ particles via ultrasonic irradiation. Chem. Commun. 2001, 1942-1943. [CrossRef] [PubMed]

23. Yu, J.C.; Zhang, L.Z.; Yu, J.G. Direct sonochemical preparation and characterization of highly active mesoporous $\mathrm{TiO}_{2}$ with a bicrystalline framework. Chem. Mater. 2002, 14, 4647-4653. [CrossRef]

24. Mahoney, L.; Rasalingam, S.; Wu, C.M.; Peng, R.; Koodali, R.T. Aging dependent phase transformation of mesostructured titanium dioxide nanomaterials prepared by evaporation-induced self-assembly process: Implications for solar hydrogen production. AIMS Mater. Sci. 2015, 2, 230-242. [CrossRef]

25. Masolo, E.; Meloni, M.; Garroni, S.; Mulas, G.; Enzo, S.; Baro, M.D.; Rossinyol, E.; Rzeszutek, A.; Herrmann-Geppert, I.; Pilo, M. Mesoporous titania powders: The role of precursors, ligand addition and calcination rate on their morphology, crystalline structure and photocatalytic activity. Nanomaterials 2014, 4, 583-598. [CrossRef]

26. Ismail, A.A.; Bahnemann, D.W. One-step synthesis of mesoporous platinum/titania nanocomposites as photocatalyst with enhanced photocatalytic activity for methanol oxidation. Green Chem. 2011, 13, 428-435. [CrossRef]

27. Atitar, M.F.; Ismail, A.A.; Al-Sayari, S.A.; Bahnemann, D.; Afanasev, D.; Emeline, A.V. Mesoporous $\mathrm{TiO}_{2}$ nanocrystals as efficient photocatalysts: Impact of calcination temperature and phase transformation on photocatalytic performance. Chem. Eng. J. 2015, 264, 417-424. [CrossRef]

28. An, H.R.; Park, S.Y.; Kim, H.; Lee, C.Y.; Choi, S.; Lee, S.C.; Seo, S.; Park, E.C.; Oh, Y.K.; Song, C.G.; et al. Advanced nanoporous $\mathrm{TiO}_{2}$ photocatalysts by hydrogen plasma for efficient solar-light photocatalytic application. Sci. Rep. 2016, 6, 29683. [CrossRef]

29. Shen, J.Y.; Wang, H.; Zhou, Y.; Ye, N.Q.; Li, G.B.; Wang, L.J. Anatase/rutile $\mathrm{TiO}_{2}$ nanocomposite microspheres with hierarchically porous structures for high-performance lithium-ion batteries. RSC Adv. 2012, 2, 9173-9178. [CrossRef]

30. Qi, L.F.; Ho, W.K.; Wang, J.L.; Zhang, P.Y.; Yu, J.G. Enhanced catalytic activity of hierarchically macro-/mesoporous $\mathrm{Pt} / \mathrm{TiO}_{2}$ toward room-temperature decomposition of formaldehyde. Catal. Sci. Technol. 2015, 5, 2366-2377. [CrossRef]

31. Xie, Y.J.; Zhang, X.; Ma, P.J.; Wu, Z.J.; Piao, L.Y. Hierarchical $\mathrm{TiO}_{2}$ photocatalysts with a one-dimensional heterojunction for improved photocatalytic activities. Nano Res. 2015, 8, 2092-2101. [CrossRef]

32. Mohamed, M.M.; Asghar, B.H.M.; Muathen, H.A. Facile synthesis of mesoporous bicrystallized TiO ${ }_{2}(\mathrm{~B}) /$ anatase (rutile) phases as active photocatalysts for nitrate reduction. Catal. Commun. 2012, 28, 58-63. [CrossRef] 
33. Zhang, W.; He, H.L.; Tian, Y.; Lan, K.; Liu, Q.; Wang, C.Y.; Liu, Y.; Elzatahry, A.; Che, R.C.; Li, W.; et al. Synthesis of uniform ordered mesoporous $\mathrm{TiO}_{2}$ microspheres with controllable phase junctions for efficient solar water splitting. Chem. Sci. 2019, 10, 1664-1670. [CrossRef] [PubMed]

34. Hou, H.L.; Shang, M.H.; Wang, L.; Li, W.E.; Tang, B.; Yang, W.Y. Efficient photocatalytic activities of TiO 2 hollow fibers with mixed phases and mesoporous walls. Sci. Rep. 2015, 5, 15228. [CrossRef] [PubMed]

35. Chen, L.; Yao, B.; Cao, Y.; Fan, K. Synthesis of well-ordered mesoporous titania with tunable phase content and high photoactivity. J. Phys. Chem. C 2007, 111, 11849-11853. [CrossRef]

36. Masolo, E.; Senes, N.; Pellicer, E.; Baro, M.D.; Enzo, S.; Pilo, M.I.; Mulas, G.; Garroni, S. Evaluation of the anatase/rutile phase composition influence on the photocatalytic performances of mesoporous $\mathrm{TiO}_{2}$ powders. Int. J. Hydrog. Energy 2015, 40, 14483-14491. [CrossRef]

37. Bai, Y.; Li, W.; Liu, C.; Yang, Z.H.; Feng, X.; Lu, X.H.; Chan, K.Y. Stability of Pt nanoparticles and enhanced photocatalytic performance in mesoporous $\mathrm{Pt}-($ anatase/TiO $2(\mathrm{~B}))$ nanoarchitecture. J. Mater. Chem. 2009, 19, 7055-7061. [CrossRef]

38. El-Sheikh, S.M.; Khedr, T.M.; Hakki, A.; Ismail, A.A.; Badawy, W.A.; Bahnemann, D.W. Visible light activated carbon and co-doped mesoporous $\mathrm{TiO}_{2}$ as efficient photocatalyst for degradation of ibuprofen. Sep. Purif. Technol. 2017, 173, 258-268. [CrossRef]

39. Khedr, T.M.; El-Sheikh, S.M.; Ismail, A.A.; Kowalska, E.; Bahnemann, D.W. Photodegradation of microcystin-LR using visible light-activated $\mathrm{C} / \mathrm{N}$-co-modified mesoporous $\mathrm{TiO}_{2}$ photocatalyst. Materials 2019, 12, 1027. [CrossRef]

40. Khedr, T.M.; El-Sheikh, S.M.; Ismail, A.A.; Bahnemann, D.W. Photodegradation of 4-aminoantipyrine over nano-titania heterojunctions using solar and LED irradiation sources. J. Environ. Chem. Eng. 2019, 7, 102797. [CrossRef]

41. Khedr, T.M.; El-Sheikh, S.M.; Hakki, A.; Ismail, A.A.; Badawy, W.A.; Bahnemann, D.W. Highly active non-metals doped mixed-phase $\mathrm{TiO}_{2}$ for photocatalytic oxidation of ibuprofen under visible light. J. Photochem. Photobiol. A 2017, 346, 530-540. [CrossRef]

42. El-Sheikh, S.M.; Khedr, T.M.; Zhang, G.S.; Vogiazi, V.; Ismail, A.A.; O'Shea, K.; Dionysiou, D.D. Tailored synthesis of anatase-brookite heterojunction photocatalysts for degradation of cylindrospermopsin under UV-Vis light. Chem. Eng. J. 2017, 310, 428-436. [CrossRef]

43. Khedr, T.M.; El-Sheikh, S.M.; Abdeldayem, H.M.; Ismail, A.A.; Kowalska, E.; Bahnemann, D.W. A comparative study of microcystin-LR degradation by UV-A, solar and visible light irradiation using bare and C/N/S-modified titania. Catalysts 2019, 9, 877. [CrossRef]

44. Neppolian, B.; Choi, H.C.; Sakthivel, S.; Arabindoo, B.; Murugesan, V. Solar/UV-induced photocatalytic degradation of three commercial textile dyes. J. Hazard. Mater. 2002, 89, 303-317. [CrossRef]

45. Mills, A.; Morris, S.; Davies, R. Photomineralisation of 4-chlorophenol sensitised by titanium dioxide: A study of the intermediates. J. Photochem. Photobiol. A Chem. 1993, 70, 183-191. [CrossRef]

46. Mozia, S.; Tomaszewska, M.; Morawski, A.W. A new photocatalytic membrane reactor (PMR) for removal of azo-dye Acid Red 18 from water. Appl. Catal. B Environ. 2005, 59, 131-137. [CrossRef]

47. Toepfer, B.; Gora, A.; Puma, G.L. Photocatalytic oxidation of multicomponent solutions of herbicides: Reaction kinetics analysis with explicit photon absorption effects. Appl. Catal. B Environ. 2006, 68, 171-180. [CrossRef]

48. Grzechulska, J.; Morawski, A.W. Photocatalytic labyrinth flow reactor with immobilized $\mathrm{P}_{2} 5 \mathrm{TiO}_{2}$ bed for removal of phenol from water. Appl. Catal. B Environ. 2003, 46, 415-419. [CrossRef]

49. Calza, P.; Minero, C.; Hiskia, A.; Papaconstantinou, E.; Pelizzetti, E. Photocatalytic transformations of CCl3Br, $\mathrm{CBr} 3 \mathrm{~F}, \mathrm{CHCl} 2 \mathrm{Br}$ and $\mathrm{CH} 2 \mathrm{BrCl}$ in aerobic and anaerobic conditions. Appl. Catal. B Environ. 2001, 29, $23-34$. [CrossRef]

50. Tahiri, H.; Aitichou, Y.; Herrmann, J.M. Photocatalytic degradation of chlorobenzoic isomers in aqueous suspensions of neat and modified titania. J. Photochem. Photobiol. A 1998, 114, 219-226. [CrossRef]

51. Ferguson, M.A.; Hering, J.G. $\mathrm{TiO}_{2}$-photocatalyzed As(III) oxidation in a fixed-bed, flow-through reactor. Environ. Sci. Technol. 2006, 40, 4261-4267. [CrossRef]

52. Yao, Z.X.; Wang, M.Q.; Sun, S.H.; Jia, R.B.; Li, H. High performance photocatalysts based on N-doped graphene-P25 for photocatalytic reduction of carbon tetrachloride. J. Inorg. Organomet. Polym. Mater. 2014, 24, 315-320. [CrossRef] 
53. Jiao, Y.C.; Jiang, H.L.; Chen, F. $\mathrm{RuO}_{2} / \mathrm{TiO}_{2} / \mathrm{Pt}$ ternary photocatalysts with epitaxial heterojunction and their application in CO oxidation. ACS Catal. 2014, 4, 2249-2257. [CrossRef]

54. Thevenet, F.; Guillard, C.; Rousseau, A. Acetylene photocatalytic oxidation using continuous flow reactor: Gas phase and adsorbed phase investigation, assessment of the photocatalyst deactivation. Chem. Eng. J. 2014, 244, 50-58. [CrossRef]

55. Sakai, H.; Kubota, Y.; Yamaguchi, K.; Fukuoka, H.; Inumaru, K. Photocatalytic decomposition of 2-propanol and acetone in air by nanocomposites of pre-formed $\mathrm{TiO}_{2}$ particles and mesoporous silica. J. Porous Mater. 2013, 20, 693-699. [CrossRef]

56. Toma, F.L.; Bertrand, G.; Chwa, S.O.; Meunier, C.; Klein, D.; Coddet, C. Comparative study on the photocatalytic decomposition of nitrogen oxides using $\mathrm{TiO}_{2}$ coatings prepared by conventional plasma spraying and suspension plasma spraying. Surf. Coat. Technol. 2006, 200, 5855-5862. [CrossRef]

57. Nishikawa, N.; Kaneco, S.; Katsumata, H.; Suzuki, T.; Ohta, K.; Yamazaki, E.; Masuyama, K.; Hashimoto, T.; Kamiya, K. Photocatalytic degradation of allergens in water with titanium dioxide. Fresenius Environ. Bull. 2007, 16, 310-314.

58. Markowska-Szczupak, A.; Wang, K.L.; Rokicka, P.; Endo, M.; Wei, Z.S.; Ohtani, B.; Morawski, A.W.; Kowalska, E. The effect of anatase and rutile crystallites isolated from titania P25 photocatalyst on growth of selected mould fungi. J. Photochem. Photobiol. B 2015, 151, 54-62. [CrossRef]

59. Markowska-Szczupak, A.; Janda, K.; Wang, K.L.; Morawski, A.W.; Kowalska, E. Effect of water activity and titania P25 photocatalyst on inactivation of pathogenic fungi-Contribution to the protection of public health. Cen. Eur. J. Public Health 2015, 23, 267-271.

60. Benabbou, A.K.; Derriche, Z.; Felix, C.; Lejeune, P.; Guillard, C. Photocatalytic inactivation of Escherischia coli - Effect of concentration of $\mathrm{TiO}_{2}$ and microorganism, nature, and intensity of UV irradiation. Appl. Catal. B Environ. 2007, 76, 257-263. [CrossRef]

61. Krishna, V.; Pumprueg, S.; Lee, S.H.; Zhao, J.; Sigmund, W.; Koopman, B.; Moudgil, B.M. Photocatalytic disinfection with titanium dioxide coated multi-wall carbon nanotubes. Process Saf. Environ. 2005, 83, 393-397. [CrossRef]

62. Thabet, S.; Weiss-Gayet, M.; Dappozze, F.; Cotton, P.; Guillard, C. Photocatalysis on yeast cells: Toward targets and mechanisms. Appl. Catal. B Environ. 2013, 140, 169-178. [CrossRef]

63. Helali, S.; Polo-Lopez, M.I.; Fernandez-Ibanez, P.; Ohtani, B.; Amano, F.; Malato, S.; Guillard, C. Solar photocatalysis: A green technology for E. coli contaminated water disinfection. Effect of concentration and different types of, suspended catalyst. J. Photochem. Photobiol. A 2014, 276, 31-40. [CrossRef]

64. Bozzi, A.; Yuranova, T.; Guasaquillo, I.; Laub, D.; Kiwi, J. Self-cleaning of modified cotton textiles by $\mathrm{TiO}_{2}$ at low temperatures under daylight irradiation. J. Photochem. Photobiol. A 2005, 174, 156-164. [CrossRef]

65. Smits, M.; Chan, C.K.; Tytgat, T.; Craeye, B.; Costarramone, N.; Lacombe, S.; Lenaerts, S. Photocatalytic degradation of soot deposition: Self-cleaning effect on titanium dioxide coated cementitious materials. Chem. Eng. J. 2013, 222, 411-418. [CrossRef]

66. Vero, N.; Hribernik, S.; Andreozzi, P.; Sfiligoj-Smole, M. Homogeneous self-cleaning coatings on cellulose materials derived from $\mathrm{TIP} / \mathrm{TiO}_{2}$ P25. Fiber Polym. 2009, 10, 716-723. [CrossRef]

67. Antoniadou, M.; Lianos, P. Production of electricity by photoelectrochemical oxidation of ethanol in a PhotoFuelCell. Appl. Catal. B Environ. 2010, 99, 307-313. [CrossRef]

68. Wang, K.L.; Wei, Z.S.; Ohtani, B.; Kowalska, E. Interparticle electron transfer in methanol dehydrogenation on platinum-loaded titania particles prepared from P25. Catal. Today 2018, 303, 327-333. [CrossRef]

69. Ohtani, B.; Prieto-Mahaney, O.O.; Li, D.; Abe, R. What is Degussa (Evonik) P25? Crystalline composition analysis, reconstruction from isolated pure particles and photocatalytic activity test. J. Photochem. Photobiol. A 2010, 216, 179-182. [CrossRef]

70. Wang, G.H.; Xu, L.; Zhang, J.; Yin, T.T.; Han, D.Y. Enhanced photocatalytic activity of $\mathrm{TiO}_{2}$ powders (P25) via calcination treatment. Int. J. Photoenergy 2012, 265760.

71. Martin, S.T.; Herrmann, H.; Choi, W.; Hoffmann, M.R. Time-resolved microwave conductivity. Part 1. TiO 2 photoreactivity and size quantization. J. Chem. Soc. Faraday Trans. 1994, 90, 3315-3322. [CrossRef]

72. Szczepankiewicz, S.H.; Colussi, A.J.; Hoffmann, M.R. Infrared spectra of photoinduced species on hydroxylated titania surfaces. J. Phys. Chem. B 2000, 104, 9842-9850. [CrossRef]

73. Ohno, T.; Sarukawa, K.; Matsumura, M. Crystal faces of rutile and anatase $\mathrm{TiO}_{2}$ particles and their roles in photocatalytic reactions. New J. Chem. 2002, 26, 1167-1170. [CrossRef] 
74. Ohno, T.; Sarukawa, K.; Tokieda, K.; Matsumura, M. Morphology of a $\mathrm{TiO}_{2}$ photocatalyst (Degussa, P 25) consisting of anatase and rutile crystalline phases. J. Catal. 2001, 203, 82-86. [CrossRef]

75. Hurum, D.C.; Gray, K.A.; Rajh, T.; Thurnauer, M.C. Recombination pathways in the Degussa P25 formulation of $\mathrm{TiO}_{2}$ : Surface versus lattice mechanisms. J. Phys. Chem. B 2005, 109, 977-980. [CrossRef] [PubMed]

76. Sclafani, A.; Palmisano, L.; Schiavello, M. Photoreduction of dinitrogen and photooxidation of phenol and nitrophenol isomers as examples of heterogeneous photocatalytic reactions. Res. Chem. Intermed. 1992, 18, 211-226. [CrossRef]

77. Yu, Y.Y.; Meng, X.; Zeng, N.; Dan, Y.; Jiang, L. Covalent immobilization of $\mathrm{TiO}_{2}$ within macroporous polymer monolith as a facilely recyclable photocatalyst for water decontamination. Colloid Polym. Sci. 2018, 296, 1419-1429. [CrossRef]

78. Janczarek, M.; Kowalska, E.; Ohtani, B. Decahedral-shaped anatase titania photocatalyst particles: Synthesis in a newly developed coaxial-flow gas-phase reactor. Chem. Eng. J. 2016, 289, 502-512. [CrossRef]

79. Theurich, J.; Lindner, M.; Bahnemann, D.W. Photocatalytic degradation of 4-chlorophenol in aerated aqueous titanium dioxide suspensions: A kinetic and mechanistic study. Langmuir 1996, 12, 6368-6376. [CrossRef]

80. Wang, C.Y.; Boettcher, C.; Bahnemann, D.W.; Dohrmann, J.K. A comparative study of nanometer sized $\mathrm{Fe}(\mathrm{III})$-doped $\mathrm{TiO}_{2}$ photocatalysts: Synthesis, characterization and activity. J. Mater. Chem. 2003, 13, 2322-2329. [CrossRef]

81. Hurum, D.C.; Agrios, A.G.; Gray, K.A.; Rajh, T.; Thurnauer, M.C. Explaining the enhanced photocatalytic activity of Degussa P25 mixed-phase $\mathrm{TiO}_{2}$ using EPR. J. Phys. Chem. B 2003, 107, 4545-4549. [CrossRef]

82. Bickley, R.I.; Gonzalez-Carreno, T.; Lees, J.S.; Palmisano, L.; Tilley, R.J.D. A structural investigation of titanium dioxide photocatalysts. J. Solid State Chem. 1991, 92, 178-190. [CrossRef]

83. Scanlon, D.O.; Dunnill, C.W.; Buckeridge, J.; Shevlin, S.A.; Logsdail, A.J.; Woodley, S.M.; Catlow, C.R.A.; Powell, M.J.; Palgrave, R.G.; Parkin, I.P.; et al. Band alignment of rutile and anatase $\mathrm{TiO}_{2}$. Nat. Mater. 2013, 12, 798-801. [CrossRef]

84. Van der Meulen, T.; Mattson, A.; Osterlund, L. A comparative study of the photocatalytic oxidation of propane on anatase, rutile, and mixed-phase anatase-rutile $\mathrm{TiO}_{2}$ nanoparticles: Role of surface intermediates. J. Catal. 2007, 251, 131-144. [CrossRef]

85. Boehme, M.; Ensinger, W. Mixed Phase Anatase/rutile titanium dioxide nanotubes for enhanced photocatalytic degradation of methylene-blue. Nano Micro Lett. 2011, 3, 236-241. [CrossRef]

86. Su, R.; Bechstein, R.; So, L.; Vang, R.T.; Sillassen, M.; Esbjornsson, B.; Palmqvist, A.; Besenbacher, F. How the Anatase-to-Rutile Ratio Influences the Photoreactivity of $\mathrm{TiO}_{2}$. J. Phys. Chem. C 2011, 115, 24287-24292. [CrossRef]

87. Zhu, Q.; Qian, J.S.; Pan, H.; Tu, L.; Zhou, X.F. Synergistic manipulation of micro-nanostructures and composition: Anatase/rutile mixed-phase $\mathrm{TiO}_{2}$ hollow micro-nanospheres with hierarchical mesopores for photovoltaic and photocatalytic applications. Nanotechnology 2011, 22, 395703. [CrossRef]

88. Wang, Q.Z.; Lian, J.H.; Bai, Y.; Hui, J.; Zhong, J.B.; Li, J.Z.; An, N.; Yu, J.; Wang, F.P. Photocatalytic activity of hydrogen production from water over $\mathrm{TiO}_{2}$ with different crystal structures. Mater. Sci. Semicond. Process. 2015, 40, 418-423. [CrossRef]

89. Semicond, C.; Ji, H.B. Comparison of $\mathrm{TiO}_{2}$ Degussa P25 with anatase and rutile crystalline phases for methane combustion. Chem. Eng. J. 2014, 243, 254-264.

90. Zhang, J.; Xu, Q.; Feng, Z.; Li, M.; Li, C. Importance of the relationship between surface phases and photocatalytic activity of $\mathrm{TiO}_{2}$. Angew. Chem. Int. Ed. 2008, 47, 1766-1769. [CrossRef]

91. Demeestere, K.; Dewulf, J.; Van Langenhove, H.; Sercu, B. Gas-solid adsorption of selected volatile organic compounds on titanium dioxide Degussa P25. Chem. Eng. Sci. 2003, 58, 2255-2267. [CrossRef]

92. Hurum, D.C.; Gray, K.A.; Rajh, T.; Thurnauer, M.C. Photoinitiated reactions of 2,4,6 TCP on Degussa P25 formulation $\mathrm{TiO}_{2}$ : Wavelength-sensitive decomposition. J. Phys. Chem. B 2004, 108, 16483-16487. [CrossRef]

93. Mi, Y.; Weng, Y.X. Band alignment and controllable electron migration between rutile and anatase $\mathrm{TiO}_{2}$. Sci. Rep. 2015, 5, 11482. [CrossRef] [PubMed]

94. Zhang, Z.; Wang, C.C.; Zakaria, R.; Ying, J.Y. Role of particle size in nanocrystalline $\mathrm{TiO}_{2}$-based photocatalysts. J. Phys. Chem. B 1998, 102, 10871-10878. [CrossRef]

95. Li, A.L.; Wang, Z.L.; Yin, H.; Wang, S.Y.; Yan, P.L.; Huang, B.K.; Wang, X.L.; Li, R.G.; Zong, X.; Han, H.X.; et al. Understanding the anatase-rutile phase junction in charge separation and transfer in a $\mathrm{TiO}_{2}$ electrode for photoelectrochemical water splitting. Chem. Sci. 2016, 7, 6076-6082. [CrossRef] [PubMed] 
96. Jiang, X.Z.; Manawan, M.; Feng, T.; Qian, R.F.; Zhao, T.; Zhou, G.D.; Kong, F.T.; Wang, Q.; Dai, S.Y.; Pan, J.H. Anatase and rutile in evonik aeroxide P25: Heterojunctioned or individual nanoparticles? Catal. Today 2018, 300, 12-17. [CrossRef]

97. Jiang, D.L.; Zhang, S.Q.; Zhao, H.J. Photocatalytic degradation characteristics of different organic compounds at $\mathrm{TiO}_{2}$ nanoporous film electrodes with mixed anatase/rutile phases. Environ. Sci. Technol. 2007, 41, 303-308. [CrossRef]

98. Xiong, Z.G.; Wu, H.; Zhang, L.H.; Gu, Y.; Zhao, X.S. Synthesis of $\mathrm{TiO}_{2}$ with controllable ratio of anatase to rutile. J. Mater. Chem. A 2014, 2, 9291-9297. [CrossRef]

99. Zhang, J.; Li, M.J.; Feng, Z.C.; Chen, J.; Li, C. UV Raman spectroscopic study on $\mathrm{TiO}_{2}$. I. Phase transformation at the surface and in the bulk. J. Phys. Chem. B 2006, 110, 927-935. [CrossRef]

100. Ohtani, B.; Azuma, Y.; Li, D.; Ihara, T.; Abe, R. Isolation of anatase crystallites from anatase-rutile mixed particles by dissolution with aqueous hydrogen peroxide and ammonia. Trans. Mater. Res. Soc. Jpn. 2007, 32, 401-404.

101. Ohno, T.; Sarukawa, K.; Matsumura, M. Photocatalytic activities of pure rutile particles isolated from $\mathrm{TiO}_{2}$ powder by dissolving the anatase component in HF solution. J. Phys. Chem. B 2001, 105, 2417-2420. [CrossRef]

102. Macounova, K.; Urban, J.; Krysova, H.; Krysa, J.; Jirkovsky, J.; Ludvik, J. Photodegradation of metamitron (4-amino-6-phenyl-3-methyl-1,2,4-triazin-5(4H)-one) on $\mathrm{TiO}_{2}$. J. Photochem. Photobiol. A 2001, 140, 93-98. [CrossRef]

103. Brigden, C.T.; Poulston, S.; Twigg, M.V.; Walker, A.P.; Wilkins, A.J.J. Photooxidation of short-chain hydrocarbons over titania. Appl. Catal. B Environ. 2001, 32, 63-71. [CrossRef]

104. Tryba, B.; Morawski, A.W.; Inagaki, M. Application of $\mathrm{TiO}_{2}$-mounted activated carbon to the removal of phenol from water. Appl. Catal. B Environ. 2003, 41, 427-433. [CrossRef]

105. Zielinska-Jurek, A.; Klein, M.; Hupka, J. Enhanced visible light photocatalytic activity of $\mathrm{Pt} / \mathrm{I}-\mathrm{TiO}_{2}$ in a slurry system and supported on glass packing. Sep. Purif. Technol. 2017, 189, 246-252. [CrossRef]

106. Hupka, J.; Zaleska, A.; Janczarek, M.; Kowalska, E.; Gorska, P.; Aranowski, R. UV/VIS light-enhanced photocatalysis for water treatment and protection. In Soil and Water Pollution Monitoring, Protection and Remediation; Earth and Environmental Sciences; Twardowska, I., Allen, H.E., Häggblom, M.M., Stefaniak, S., Eds.; Springer: Berlin, Germany, 2006; Volume Nato Science Series: IV; pp. 151-166.

107. Kowalska, E. Investigation of Photochemical Degradation of Organic Compounds. Ph.D. Thesis, Gdansk University of Technology, Gdansk, Poland, 2004.

108. Kowalska, E.; Rau, S. Photoreactors for wastewater treatment: A review. Recent Pat. Eng. 2010, 4, $242-266$. [CrossRef]

109. Zielinska-Jurek, A.; Bielan, Z.; Wysocka, I.; Strychalska, J.; Janczarek, M.; Klimczuk, T. Magnetic semiconductor photocatalysts for the degradation of recalcitrant chemicals from flow back water. J. Environ. Manag. 2017, 195, 157-165. [CrossRef]

110. Zielinska-Jurek, A.; Bielan, Z.; Dudziak, S.; Wolak, I.; Sobczak, Z.; Klimczuk, T.; Nowaczyk, G.; Hupka, J. Design and application of magnetic photocatalysts for water treatment. The effect of particle charge on surface functionality. Catalysts 2017, 7, 360. [CrossRef]

111. Wysocka, I.; Kowalska, E.; Trzcinski, K.; Lapinski, M.; Nowaczyk, G.; Zielinska-Jurek, A. UV-Vis-Induced degradation of phenol over magnetic photocatalysts modified with $\mathrm{Pt}, \mathrm{Pd}, \mathrm{Cu}$ and $\mathrm{Au}$ nanoparticles. Nanomaterials 2018, 8, 28. [CrossRef]

112. Yang, H.G.; Sun, C.H.; Qiao, S.Z.; Zou, J.; Liu, G.; Smith, S.C.; Cheng, H.M.; Lu, G.Q. Anatase TiO 2 single crystals with a large percentage of reactive facets. Nature 2008, 453, 638-641. [CrossRef]

113. Vittadini, A.; Selloni, A.; Rotzinger, F.P.; Gratzel, M. Structure and energetics of water adsorbed at $\mathrm{TiO}_{2}$ anatase (101) and (001) surfaces. Phys. Rev. Lett. 1998, 81, 2954-2957. [CrossRef]

114. Liu, G.; Yu, J.C.; Lu, G.Q.; Cheng, H.M. Crystal facet engineering of semiconductor photocatalysts: Motivations, advances and unique properties. Chem. Commun. 2011, 47, 6763-6783. [CrossRef] [PubMed]

115. Kou, J.H.; Lu, C.H.; Wang, J.; Chen, Y.K.; Xu, Z.Z.; Varma, R.S. Selectivity enhancement in heterogeneous photocatalytic transformations. Chem. Rev. 2017, 117, 1445-1514. [CrossRef] [PubMed]

116. Lazzeri, M.; Vittadini, A.; Selloni, A. Structure and energetics of stoichiometric $\mathrm{TiO}_{2}$ anatase surfaces. Phys. Rev. B 2001, 63, 155409. [CrossRef] 
117. Liu, G.; Yang, H.G.; Pan, J.; Yang, Y.Q.; Lu, G.Q.; Cheng, H.M. Titanium dioxide crystals with tailored facets. Chem. Rev. 2014, 114, 9559-9612. [CrossRef] [PubMed]

118. Ramamoorthy, M.; Vanderbilt, A. First-principles calculations of the energetics of stoichiometric $\mathrm{TiO}_{2}$ surfaces. Phys. Rev. B 1994, 49, 16721-16727. [CrossRef] [PubMed]

119. Gong, X.Q.; Selloni, A. First-principles study of the structures and energetics of stoichiometric brookite $\mathrm{TiO}_{2}$ surfaces. Phys. Rev. B 2007, 76, 235307. [CrossRef]

120. Yang, H.G.; Liu, G.; Qiao, S.Z.; Sun, C.H.; Jin, Y.G.; Smith, S.C.; Zou, J.; Cheng, H.M.; Lu, G.Q. Solvothermal synthesis and photoreactivity of anatase $\mathrm{TiO}_{2}$ nanosheets with dominant $\{001\}$ facets. J. Am. Chem. Soc. 2009, 131, 4078-4083. [CrossRef]

121. Murakami, N.; Kurihara, Y.; Tsubota, T.; Ohno, T. Shape-controlled anatase titanium(IV) oxide particles prepared by hydrothermal treatment of peroxo Titanic Acid in the Presence of Polyvinyl Alcohol. J. Phys. Chem. C 2009, 113, 3062-3069. [CrossRef]

122. Han, X.G.; Wang, X.; Xie, S.F.; Kuang, Q.; Ouyang, J.J.; Xie, Z.X.; Zheng, L.S. Carbonate ions-assisted syntheses of anatase $\mathrm{TiO}_{2}$ nanoparticles exposed with high energy (001) facets. RSC Adv. 2012, 2, 3251-3253. [CrossRef]

123. Murakami, N.; Katayama, S.; Nakamura, M.; Tsubota, T.; Ohno, T. Dependence of photocatalytic activity on aspect ratio of shape-controlled rutile titanium(IV) oxide nanorods. J. Phys. Chem. C 2011, 115, 419-424. [CrossRef]

124. Dinh, C.T.; Nguyen, T.D.; Kleitz, F.; Do, T.O. Shape-controlled synthesis of highly crystalline titania nanocrystals. ACS Nano 2009, 3, 3737-3743. [CrossRef] [PubMed]

125. Amano, F.; Prieto-Mahaney, O.O.; Terada, Y.; Yasumoto, T.; Shibayama, T.; Ohtani, B. Decahedral single-crystalline particles of anatase titanium(IV) oxide with high photocatalytic activity. Chem. Mater. 2009, 21, 2601-2603. [CrossRef]

126. Tachikawa, T.; Yamashita, S.; Majima, T. Evidence for crystal-face-dependent $\mathrm{TiO}_{2}$ photocatalysis from single-molecule imaging and kinetic analysis. J. Am. Chem. Soc. 2011, 133, 7197-7204. [CrossRef] [PubMed]

127. Kobayashi, K.; Takashima, M.; Takase, M.; Ohtani, B. Mechanistic study on facet-dependent deposition of metal nanoparticles on decahedral-shaped anatase titania photocatalyst particles. Catalysts 2018, 8, 542. [CrossRef]

128. Wei, Z.; Kowalska, E.; Verrett, J.; Colbeau-Justin, C.; Remita, H.; Ohtani, B. Morphology-dependent photocatalytic activity of octahedral anatase particles prepared by ultrasonication-hydrothermal reaction of titanates. Nanoscale 2015, 7, 12392-12404. [CrossRef]

129. Wei, Z.S.; Kowalska, E.; Ohtani, B. Enhanced photocatalytic activity by particle morphology: Preparation, characterization, and photocatalytic activities of octahedral anatase titania particles. Chem. Lett. 2014, 43, 346-348. [CrossRef]

130. Kowalski, D.; Schmuki, P. Polypyrrole self-organized nanopore arrays formed by controlled electropolymerization in TiO2 nanotube template. Chem. Commun. 2010, 46, 8585-8587. [CrossRef]

131. Kozak, M.; Mazierski, P.; Zebrowska, J.; Kobylanski, M.; Klimczuk, T.; Lisowski, W.; Trykowski, G.; Nowaczyk, G.; Zaleska-Medynska, A. Electrochemically obtained $\mathrm{TiO}_{2} / \mathrm{CuxOy}$ nanotube arrays presenting a photocatalytic response in processes of pollutants degradation and bacteria inactivation in aqueous phase. Catalysts 2018, 8, 237. [CrossRef]

132. Mazierski, P.; Malankowska, A.; Kobylanski, M.; Diak, M.; Kozak, M.; Winiarski, M.J.; Klimczuk, T.; Lisowski, W.; Nowaczyk, G.; Zaleska-Medynska, A. Photocatalytically active $\mathrm{TiO}_{2} / \mathrm{Ag}_{2} \mathrm{O}$ nanotube arrays interlaced with silver nanoparticles obtained from the one-step anodic oxidation of Ti-Ag alloys. ACS Catal. 2017, 7, 2753-2764. [CrossRef]

133. Nischk, M.; Mazierski, P.; Wei, Z.S.; Siuzdak, K.; Kouame, N.A.; Kowalska, E.; Remita, H.; Zaleska-Medynska, A. Enhanced photocatalytic, electrochemical and photoelectrochemical properties of $\mathrm{TiO}_{2}$ nanotubes arrays modified with $\mathrm{Cu}, \mathrm{AgCu}$ and $\mathrm{Bi}$ nanoparticles obtained via radiolytic reduction. Appl. Surf. Sci. 2016, 387, 89-102. [CrossRef]

134. Kasuga, T.; Hiramatsu, M.; Hoson, A.; Sekino, T.; Niihara, K. Titania nanotubes prepared by chemical processing. Adv. Mater 1999, 11, 1307-1311. [CrossRef]

135. Kasuga, T.; Hiramatsu, M.; Hoson, A.; Sekino, T.; Niihara, K. Formation of titanium oxide nanotube. Langmuir 1998, 14, 3160-3163. [CrossRef]

136. Imai, H.; Takei, Y.; Shimizu, K.; Matsuda, M.; Hirashima, H. Direct preparation of anatase $\mathrm{TiO}_{2}$ nanotubes in porous alumina membranes. J. Mater. Chem. 1999, 9, 2971-2972. [CrossRef] 
137. Gong, D.; Grimes, C.A.; Varghese, O.K.; Hu, W.; Singh, R.S.; Chen, Z.; Dickey, E.C. Titanium oxide nanotube arrays prepared by anodic oxidation. J. Mater. Res. 2001, 16, 3331-3334. [CrossRef]

138. Beranek, R.; Tsuchiya, H.; Sugishima, T.; Macak, J.M.; Taveira, L.; Fujimoto, S.; Kisch, H.; Schmuki, P. Enhancement and limits of the photoelectrochemical response from anodic $\mathrm{TiO}_{2}$ nanotubes. Appl. Phys. Lett. 2005, 87, 243114. [CrossRef]

139. Balaur, E.; Macak, J.M.; Taveira, L.; Schmuki, P. Tailoring the wettability of $\mathrm{TiO}_{2}$ nanotube layers. Electrochem. Commun. 2005, 7, 1066-1070. [CrossRef]

140. Mor, G.K.; Shankar, K.; Paulose, M.; Varghese, O.K.; Grimes, C.A. Use of highly-ordered $\mathrm{TiO}_{2}$ nanotube arrays in dye-sensitized solar cells. Nano Lett. 2006, 6, 215-218. [CrossRef]

141. Shankar, K.; Basham, J.I.; Allam, N.K.; Varghese, O.K.; Mor, G.K.; Feng, X.J.; Paulose, M.; Seabold, J.A.; Choi, K.S.; Grimes, C.A. Recent advances in the use of $\mathrm{TiO}_{2}$ nanotube and nanowire arrays for oxidative photoelectrochemistry. J. Phys. Chem. C 2009, 113, 6327-6359. [CrossRef]

142. Ghicov, A.; Schmuki, P. Self-ordering electrochemistry: A review on growth and functionality of $\mathrm{TiO}_{2}$ nanotubes and other self-aligned MOx structures. Chem. Commun. 2009, 20, 2791-2808. [CrossRef]

143. Regonini, D.; Bowen, C.R.; Jaroenworaluck, A.; Stevens, R. A review of growth mechanism, structure and crystallinity of anodized $\mathrm{TiO}_{2}$ nanotubes. Mater. Sci. Eng. R 2013, 74, 377-406. [CrossRef]

144. Mohamed, A.E.; Rohani, S. Modified $\mathrm{TiO}_{2}$ nanotube arrays (TNTAs): Progressive strategies towards visible light responsive photoanode, a review. Energy Environ. Sci. 2011, 4, 1065-1086. [CrossRef]

145. Yablonovitch, E. Photonic Band-Gap Structures. J. Opt. Soc. Am. B 1993, 10, 283-295. [CrossRef]

146. Lopez, C. Materials aspects of photonic crystals. Adv. Mater. 2003, 15, 1679-1704. [CrossRef]

147. Kim, W.T.; Choi, W.Y. Fabrication of $\mathrm{TiO}_{2}$ photonic crystal by anodic oxidation and their optical sensing properties. Sens. Actuators A Phys. 2017, 260, 178-184. [CrossRef]

148. Chiarello, G.L.; Zuliani, A.; Ceresoli, D.; Martinazzo, R.; Selli, E. Exploiting the photonic crystal properties of $\mathrm{TiO}_{2}$ nanotube arrays to enhance photocatalytic hydrogen production. ACS Catal. 2016, 6, 1345-1353. [CrossRef]

149. Zhang, Z.H.; Yang, X.L.; Hedhili, M.N.; Ahmed, E.; Shi, L.; Wang, P. Microwave-assisted self-doping of $\mathrm{TiO}_{2}$ photonic crystals for efficient photoelectrochemical water splitting. ACS Appl. Mater. Interfaces 2014, 6, 691-696. [CrossRef]

150. Zhang, Z.H.; Wu, H.J. Multiple band light trapping in ultraviolet, visible and near infrared regions with $\mathrm{TiO}_{2}$ based photonic materials. Chem. Commun. 2014, 50, 14179-14182. [CrossRef]

151. Li, Z.Z.; Xin, Y.M.; Wu, W.L.; Fu, B.H.; Zhang, Z.H. Phosphorus cation doping: A new strategy for boosting photoelectrochemical performance on $\mathrm{TiO}_{2}$ nanotube photonic crystals. ACS Appl. Mater. Interfaces 2016, 8 , 30972-30979. [CrossRef]

152. Deng, X.Q.; Zhu, X.B.; Sun, Z.G.; Li, X.S.; Liu, J.L.; Shi, C.; Zhu, A.M. Exceptional activity for photocatalytic mineralization of formaldehyde over amorphous titania nanofilms. Chem. Eng. J. 2016, 306, 1001-1009. [CrossRef]

153. Baba, K.; Bulou, S.; Quesada-Gonzalez, M.; Bonot, S.; Collard, D.; Boscher, N.D.; Choquet, P. Significance of a noble metal nanolayer on the UV and visible light photocatalytic activity of anatase $\mathrm{TiO}_{2}$ thin films grown from a scalable PECVD/PVD approach. ACS Appl. Mater. Interfaces 2017, 9, 41200-41209. [CrossRef]

154. Das, S.K.; Schwanke, C.; Pfuch, A.; Seeber, W.; Bock, M.; Steinmeyer, G.; Elsaesser, T.; Grunwald, R. Highly efficient THG in $\mathrm{TiO}_{2}$ nanolayers for third-order pulse characterization. Opt. Express 2011, 19, 16985-16995. [CrossRef] [PubMed]

155. Habazaki, H.; Oikawa, Y.; Fushimi, K.; Shimizu, K.; Nagata, S.; Skeldon, P.; Thompson, G.E. Formation of porous anodic films on Ti-Si alloys in hot phosphate-glycerol electrolyte. Electrochim. Acta 2007, 53, 1775-1781. [CrossRef]

156. Darko, S.A.; Maxwell, E.; Park, S. Photocatalytic activity of $\mathrm{TiO}_{2}$ nanofilms deposited onto polyvinyl chloride and glass substrates. Thin Solid Films 2010, 519, 174-177. [CrossRef]

157. Guo, W.; Feng, Q.Q.; Tao, Y.F.; Zheng, L.J.; Han, Z.Y.; Ma, J.M. Systematic investigation on the gas-sensing performance of $\mathrm{TiO} 2$ nanoplate sensors for enhanced detection on toxic gases. Mater. Res. Bull. 2016, 73, 302-307. [CrossRef]

158. Giovannetti, R.; Rommozzi, E.; Zannotti, M.; D'Amato, C.A. Recent advances in graphene based $\mathrm{TiO}_{2}$ nanocomposites (GTiO2Ns) for photocatalytic degradation of synthetic dyes. Catalysts 2017, 7, 305. [CrossRef] 
159. Kusiak-Nejman, E.; Morawski, A.W. $\mathrm{TiO}_{2} /$ graphene-based nanocomposites for water treatment: A brief overview of charge carrier transfer, antimicrobial and photocatalytic performance. Appl. Catal. B Environ. 2019, 253, 179-186. [CrossRef]

160. Schneider, M.; Baiker, A. High-surface-area titania aerogels-Preparation and structural-properties. J. Mater. Chem. 1992, 2, 587-589. [CrossRef]

161. Campbell, L.K.; Na, B.K.; Ko, E.I. Synthesis and characterization of titania aerogels. Chem. Mater. 1992, 4, 1329-1333. [CrossRef]

162. Malinowska, B.; Walendziewski, J.; Robert, D.; Weber, J.V.; Stolarski, M. Titania aerogels: Preparation and photocatalytic tests. Int. J. Photoenergy 2003, 5, 147-152. [CrossRef]

163. Subrt, J.; Plizingrova, E.; Palkovska, M.; Bohacek, J.; Klementova, M.; Kupcik, J.; Bezdicka, P.; Sovova, H. Titania aerogels with tailored nano and microstructure: Comparison of lyophilization and supercritical drying. Pure Appl. Chem. 2017, 89, 501-509. [CrossRef]

164. Kowalska, E. Plasmonic photocatalysis. In Gold Nanoparticles for Physics, Chemistry and Biology, 2nd ed.; Louis, C., Pluchery, O., Eds.; World Scientific: Singapore, 2017; pp. 319-364.

165. DeSario, P.A.; Pietron, J.J.; DeVantier, D.E.; Brintlinger, T.H.; Stroud, R.M.; Rolison, D.R. Plasmonic enhancement of visible-light water splitting with $\mathrm{Au}-\mathrm{TiO}_{2}$ composite aerogels. Nanoscale 2013, 5, 8073-8083. [CrossRef] [PubMed]

166. Panayotov, D.A.; DeSario, P.A.; Pietron, J.J.; Brintlinger, T.H.; Szymczak, L.C.; Rolison, D.R.; Morris, J.R. Ultraviolet and visible photochemistry of methanol at 3D mesoporous networks: $\mathrm{TiO}_{2}$ and $\mathrm{Au}-\mathrm{TiO}_{2}$. J. Phys. Chem. C 2013, 117, 15035-15049. [CrossRef]

167. Likodimos, V. Photonic crystal-assisted visible light activated $\mathrm{TiO}_{2}$ photocatalysis. Appl. Catal. B Environ. 2018, 230, 269-303. [CrossRef]

168. Li, X.; Yu, J.G.; Jaroniec, M. Hierarchical photocatalysts. Chem. Soc. Rev. 2016, 45, 2603-2636. [CrossRef]

169. Chiang, C.C.; Tuyen, L.D.; Ren, C.R.; Chau, L.K.; Wu, C.Y.; Huang, P.J.; Hsu, C.C. Fabrication of titania inverse opals by multi-cycle dip-infiltration for optical sensing. Photonics Nanostructures Fundam. Appl. 2016, 19, 48-54. [CrossRef]

170. Lu, X.Y.; Zhu, Y.; Cen, T.Z.; Jiang, L. Centimeter-scale colloidal crystal belts via robust self-assembly strategy. Langmuir 2012, 28, 9341-9346. [CrossRef]

171. Jiang, P.; Bertone, J.F.; Hwang, K.S.; Colvin, V.L. Single-crystal colloidal multilayers of controlled thickness. Chem. Mater. 1999, 11, 2132-2140. [CrossRef]

172. Li, H.; Vienneau, G.; Jones, M.; Subramanian, B.; Robichaud, J.; Djaoued, Y. Crack-free 2D-inverse opal anatase $\mathrm{TiO}_{2}$ films on rigid and flexible transparent conducting substrates: Low temperature large area fabrication and electrochromic properties. J. Mater. Chem. C 2014, 2, 7804-7810. [CrossRef]

173. Mayoral, R.; Requena, J.; Moya, J.S.; Lopez, C.; Cintas, A.; Miguez, H.; Meseguer, F.; Vazquez, L.; Holgado, M.; Blanco, A. 3D long-range ordering in an $\mathrm{SiO}_{2}$ submicrometer-sphere sintered superstructure. Adv. Mater. 1997, 9, 257-260. [CrossRef]

174. Zhang, Y.X.; Quan, M.H.; Zhao, W.D.; Yang, Z.; Wang, D.; Cao, H.; He, W.L. Preferential self-assembly behavior of polydisperse silica particles under negative pressure. Colloid Surf. A 2017, 529, 832-839. [CrossRef]

175. Zhang, J.H.; Liu, H.Y.; Wang, Z.L.; Ming, N.B. Assembly of high-quality colloidal crystals under negative pressure. J. Appl. Phys. 2008, 103, 013517. [CrossRef]

176. Kubrin, R.; Pasquarelli, R.M.; Waleczek, M.; Lee, H.S.; Zierold, R.; do Rosario, J.J.; Dyachenko, P.N.; Moreno, J.M.M.; Petrov, A.Y.; Janssen, R.; et al. Bottom-up fabrication of multilayer stacks of 3D photonic crystals from titanium dioxide. ACS Appl. Mater. Interfaces 2016, 8, 10466-10476. [CrossRef] [PubMed]

177. Curti, M.; Robledo, G.L.; Claro, P.C.D.; Ubogui, J.H.; Mendive, C.B. Characterization of titania inverse opals prepared by two distinct infiltration approaches. Mater. Res. Bull. 2018, 101, 12-19. [CrossRef]

178. Zhang, Y.; Li, K.; Su, F.Y.; Cai, Z.Y.; Liu, J.X.; Wu, X.W.; He, H.L.; Yin, Z.; Wang, L.H.; Wang, B.; et al. Electrically switchable photonic crystals based on liquid-crystal-infiltrated $\mathrm{TiO}_{2}$-inverse opals. Opt. Express 2019, 27, 15391-15398. [CrossRef] [PubMed]

179. Kim, K.; Thiyagarajan, P.; Ahn, H.J.; Kim, S.I.; Jang, J.H. Optimization for visible light photocatalytic water splitting: Gold-coated and surface-textured $\mathrm{TiO}_{2}$ inverse opal nano-networks. Nanoscale 2013, 5, 6254-6260. [CrossRef]

180. Zhou, Q.; Dong, P.; Liu, L.X.; Cheng, B.Y. Study on the sedimentation self-assembly of colloidal $\mathrm{SiO}_{2}$ particles under gravitational field. Colloid Surf. A 2005, 253, 169-174. [CrossRef] 
181. Hua, C.X.; Xu, H.B.; Zhang, P.P.; Chen, X.Y.; Lu, Y.Y.; Gan, Y.; Zhao, J.P.; Li, Y. Process optimization and optical properties of colloidal self-assembly via refrigerated centrifugation. Colloid Polym. Sci. 2017, 295, 1655-1662. [CrossRef]

182. Miguez, H.; Meseguer, F.; Lopez, C.; Blanco, A.; Moya, J.S.; Requena, J.; Mifsud, A.; Fornes, V. Control of the photonic crystal properties of fcc-packed submicrometer $\mathrm{SiO}_{2}$ spheres by sintering. Adv. Mater. 1998, 10, 480-483. [CrossRef]

183. Jovic, V.; Idriss, H.; Waterhouse, G.I.N. Slow photon amplification of gas-phase ethanol photo-oxidation in titania inverse opal photonic crystals. Chem. Phys. 2016, 479, 109-121. [CrossRef]

184. Cheng, C.W.; Karuturi, S.K.; Liu, L.J.; Liu, J.P.; Li, H.X.; Su, L.T.; Tok, A.I.Y.; Fan, H.J. Quantum-dot-sensitized $\mathrm{TiO}_{2}$ inverse opals for photoelectrochemical hydrogen generation. Small 2012, 8, 37-42. [CrossRef]

185. Liu, L.J.; Karuturi, S.K.; Su, L.T.; Tok, A.I.Y. $\mathrm{TiO}_{2}$ inverse-opal electrode fabricated by atomic layer deposition for dye-sensitized solar cell applications. Energy. Environ. Sci. 2011, 4, 209-215. [CrossRef]

186. Li, X.H.; Wu, Y.; Shen, Y.H.; Sun, Y.; Yang, Y.; Xie, A.J. A novel bifunctional Ni-doped $\mathrm{TiO}_{2}$ inverse opal with enhanced SERS performance and excellent photocatalytic activity. Appl. Surf. Sci. 2018, 427, 739-744. [CrossRef]

187. Moon, J.H.; Cho, Y.S.; Yang, S.M. Room temperature chemical vapor deposition for fabrication of titania inverse opals: Fabrication, morphology analysis and optical characterization. Bull. Korean Chem. Soc. 2009, 30, 2245-2248.

188. Curti, M.; Mendive, C.B.; Grela, M.A.; Bahnemann, D.W. Stopband tuning of $\mathrm{TiO}_{2}$ inverse opals for slow photon absorption. Mater. Res. Bull. 2017, 91, 155-165. [CrossRef]

189. Sordello, F.; Duca, C.; Maurino, V.; Minero, C. Photocatalytic metamaterials: $\mathrm{TiO}_{2}$ inverse opals. Chem. Commun. 2011, 47, 6147-6149. [CrossRef]

190. Wu, M.; Liu, J.; Jin, J.; Wang, C.; Huang, S.Z.; Deng, Z.; Li, Y.; Su, B.L. Probing significant light absorption enhancement of titania inverse opal films for highly exalted photocatalytic degradation of dye pollutants. Appl. Catal. B Environ. 2014, 150, 411-420. [CrossRef]

191. Lu, Y.; Yu, H.T.; Chen, S.; Quan, X.; Zhao, H.M. Integrating plasmonic nanoparticles with $\mathrm{TiO}_{2}$ photonic crystal for enhancement of visible-light-driven photocatalysis. Environ. Sci. Technol. 2012, 46, 1724-1730. [CrossRef]

192. Curti, M.; Zvitco, G.; Grela, M.A.; Mendive, C.B. Angle dependence in slow photon photocatalysis using $\mathrm{TiO}_{2}$ inverse opals. Chem. Phys. 2018, 502, 33-38. [CrossRef]

193. Zhao, Y.X.; Yang, B.F.; Xu, J.; Fu, Z.P.; Wu, M.; Li, F. Facile synthesis of Ag nanoparticles supported on $\mathrm{TiO}_{2}$ inverse opal with enhanced visible-light photocatalytic activity. Thin Solid Films 2012, 520, 3515-3522. [CrossRef]

194. Ye, J.; He, J.H.; Wang, S.; Zhou, X.J.; Zhang, Y.; Liu, G.; Yang, Y.F. Nickel-loaded black $\mathrm{TiO}_{2}$ with inverse opal structure for photocatalytic reduction of $\mathrm{CO}_{2}$ under visible light. Sep. Purif. Technol. 2019, 220, 8-15. [CrossRef]

195. Wang, X.Y.; Li, J.; Gao, X.N.; Shen, Y.H.; Xie, A.J. Ordered CdSe-sensitized $\mathrm{TiO}_{2}$ inverse opal film as multifunctional surface-enhanced Raman scattering substrate. Appl. Surf. Sci. 2019, 463, 357-362. [CrossRef]

196. Zheng, X.Z.; Li, D.Z.; Li, X.F.; Chen, J.; Cao, C.S.; Fang, J.L.; Wang, J.B.; He, Y.H.; Zheng, Y. Construction of $\mathrm{ZnO} / \mathrm{TiO}_{2}$ photonic crystal heterostructures for enhanced photocatalytic properties. Appl. Catal. B Environ. 2015, 168, 408-415. [CrossRef]

197. Srinivasan, M.; White, T. Degradation of methylene blue by three-dimensionally ordered macroporous titania. Environ. Sci. Technol. 2007, 41, 4405-4409. [CrossRef] [PubMed]

198. Wan, Y.; Wang, J.; Wang, X.; Xu, H.; Yuan, S.; Zhang, Q.; Zhang, M. Preparation of inverse opal titanium dioxide for photocatalytic performance research. Opt. Mater. 2019, 96, 109287. [CrossRef]

199. Rahul, T.K.; Sandhyarani, N. Nitrogen-fluorine co-doped titania inverse opals for enhanced solar light driven photocatalysis. Nanoscale 2015, 7, 18259-18270. [CrossRef] [PubMed]

200. Zheng, X.Z.; Li, D.Z.; Li, X.F.; Yu, L.H.; Wang, P.; Zhang, X.Y.; Fang, J.L.; Shao, Y.; Zheng, Y. Photoelectrocatalytic degradation of Rhodamine B on $\mathrm{TiO}_{2}$ photonic crystals. Phys. Chem. Chem. Phys. 2014, 16, 15299-15306. [CrossRef] [PubMed]

201. Waterhouse, G.I.N.; Wahab, A.K.; Al-Oufi, M.; Jovic, V.; Anjum, D.H.; Sun-Waterhouse, D.; Llorca, J.; Idriss, H. Hydrogen production by tuning the photonic band gap with the electronic band gap of $\mathrm{TiO}_{2}$. Sci. Rep. 2013, 3, 2849. [CrossRef] 
202. Rahul, T.K.; Sandhyarani, N. In situ gold-loaded fluorinated titania inverse opal photocatalysts for enhanced solar-light-driven hydrogen production. ChemNanoMat 2017, 3, 503-510. [CrossRef]

203. Cai, J.M.; Wu, M.Q.; Wang, Y.T.; Zhang, H.; Meng, M.; Tian, Y.; Li, X.G.; Zhang, J.; Zheng, L.R.; Gong, J.L. Synergetic enhancement of light harvesting and charge separation over surface-disorder-engineered $\mathrm{TiO}_{2}$ photonic crystals. Chem 2017, 2, 877-892. [CrossRef]

204. Zhou, L.; O’Brien, P. Mesocrystals-Properties and Applications. J. Phys. Chem. Lett. 2012, 3, $620-628$. [CrossRef]

205. Li, L.; Liu, C.Y. Organic small molecule-assisted synthesis of high active $\mathrm{TiO}_{2}$ rod-like mesocrystals. CrystEngComm 2010, 12, 2073-2078. [CrossRef]

206. Sturm, E.V.; Cölfen, H. Mesocrystals: Structural and morphogenetic aspects. Chem. Soc. Rev. 2016, 45, 5821-5833. [CrossRef] [PubMed]

207. Konstantinova, E.; Minnekhanov, A.; Beltiukov, A.; Ivanov, V.; Sutherland, A.J.; Boytsova, O. Unveiling point defects in titania mesocrystals: A combined EPR and XPS study. New J. Chem. 2018, 42, 15184-15189. [CrossRef]

208. Hu, H.; Yang, Y.; Ou, Y.; Liu, B.; Li, J.; Yuan, W.; Wang, Y.; Zhang, Z. Early stage growth of rutile titania mesocrystals. Cryst. Growth Des. 2018, 18, 4209-4214.

209. Bian, Z.F.; Tachikawa, T.; Zhang, P.; Fujitsuka, M.; Majima, T. Au/ $\mathrm{TiO}_{2}$ superstructure-based plasmonic photocatalysts exhibiting efficient charge separation and unprecedented activity. J. Am. Chem. Soc. 2014, 136, 458-465. [CrossRef]

210. Ao, Y.H.; Xu, J.L.; Gao, Y.Y.; Wang, P.F.; Wang, C.; Hou, J.; Qian, J. Preparation of Ag nanoparticles loaded $\mathrm{TiO}_{2}$ nanoplate arrays on activated carbon fibers with enhanced photocatalytic activity. Catal. Commun. 2014, 53, 21-24. [CrossRef]

(C) 2019 by the authors. Licensee MDPI, Basel, Switzerland. This article is an open access article distributed under the terms and conditions of the Creative Commons Attribution (CC BY) license (http://creativecommons.org/licenses/by/4.0/). 